\title{
Akkermansia muciniphila in the Human Gastrointestinal Tract: When, Where, and How?
}

\author{
Sharon Y. Geerlings ${ }^{1}$, Ioannis Kostopoulos ${ }^{1}$, Willem M. de Vos ${ }^{1,2}$ and Clara Belzer ${ }^{1, *}$ \\ 1 Laboratory of Microbiology, Wageningen University and Research, Stippeneng 4, 6708WE Wageningen, \\ The Netherlands; sharon.geerlings@wur.nl (S.Y.G.); ioannis.kostopoulos@wur.nl (I.K.); \\ willem.devos@wur.nl (W.M.d.V.) \\ 2 Immunobiology Research Program, Department of Bacteriology and Immunology, Haartman Institute, \\ University of Helsinki, 00014 Helsinki, Finland \\ * Correspondence: clara.belzer@wur.nl; Tel.: +31-317-483-742
}

Received: 1 June 2018; Accepted: 12 July 2018; Published: 23 July 2018

\begin{abstract}
Akkermansia muciniphila is a mucin-degrading bacterium of the phylum Verrucomicrobia. Its abundance in the human intestinal tract is inversely correlated to several disease states. A. muciniphila resides in the mucus layer of the large intestine, where it is involved in maintaining intestinal integrity. We explore the presence of Akkermansia-like spp. based on its 16S rRNA sequence and metagenomic signatures in the human body so as to understand its colonization pattern in time and space. A. muciniphila signatures were detected in colonic samples as early as a few weeks after birth and likely could be maintained throughout life. The sites where Akkermansia-like sequences (including Verrucomicrobia phylum and/or Akkermansia spp. sequences found in the literature) were detected apart from the colon included human milk, the oral cavity, the pancreas, the biliary system, the small intestine, and the appendix. The function of Akkermansia-like spp. in these sites may differ from that in the mucosal layer of the colon. A. muciniphila present in the appendix or in human milk could play a role in the re-colonization of the colon or breast-fed infants, respectively. In conclusion, even though A. muciniphila is most abundantly present in the colon, the presence of Akkermansia-like spp. along the digestive tract indicates that this bacterium might have more functions than those currently known.
\end{abstract}

Keywords: Akkermansia muciniphila; mucin; gut microbiota; ecological niches; digestive tract; human breast milk

\section{Introduction}

The microbial community in the human gut plays a role in the balance between health and disease. The gastrointestinal (GI) microbiota has recently emerged as an important factor in human physiology, both under homeostatic and pathological conditions [1]. Characterization of the GI microbiota may identify gut-related abnormalities and play an important role in establishing functional linkages to health status [2]. Some GI tract disorders with associated microbiota imbalance include celiac disease [2], irritable bowel syndrome (IBS) [3,4], inflammatory bowel disease (IBD) [5-7], and type 2 diabetes (T2D) [8-10].

The A. muciniphila-type strain Muc ${ }^{\mathrm{T}}$ of the phylum Verrucomicrobia was first described in 2004 [11]. This bacterium was isolated from the fecal sample of a healthy individual using purified mucin as the sole source of carbon, nitrogen, and energy for growth. A. muciniphila has only a few similarities to other representatives of Verrucomicrobia [12]. Interestingly, Akkermansia is the only genus of the Verrucomicrobia phylum found in gastrointestinal samples. Large differences were observed between verrucomicrobial genomes, in terms of the GC content and genome sizes. In contrast, similarities were 
observed within the Verrucomicrobia phylum as a large proportion of the proteins in verrucomicrobial proteomes were found to contain signal peptides $(26.1 \%$ for $A$. muciniphila). In the colon of a healthy human being, A. muciniphila is present in high levels with an abundance of approximately $3 \%[6,13]$. The core activity of $A$. muciniphila is to degrade mucus using the many mucolytic enzymes encoded in its genome $[6,12]$.

The presence of $A$. muciniphila has been associated with healthy intestine and its abundance has been inversely correlated to several disease states [6-8,14-16]. For example, in cases of IBD (patients with ulcerative colitis and Crohn's disease), the abundance of A. muciniphila was found to be decreased [6,7]. Also, individuals with acute appendicitis were found to harbor a decreased amount of A. muciniphila [14]. In this case, the abundance of $A$. muciniphila was inversely related to the severity of the appendicitis. Furthermore, obese children were shown to have a significant reduction in A. muciniphila-like bacteria [15]. In a comprehensive study of infants in daycare, A. muciniphila-based sequences were found to be reduced in children that had received multiple antibiotic courses and were at risk for later life obesity [17]. In concordance with these studies, another reported the association of A. muciniphila with a healthier metabolic status in obese and overweight individuals [16]. Moreover, the genus Akkermansia and its metabolic pathways were found to be enriched in athletes with a low body mass index $[18,19]$. Lastly, the abundance of Verrucomicrobiae was significantly reduced in pre-diabetes and T2D [8]. It is important to note that these diseases may have an effect on the integrity or thickness of the mucus layer, and thereby effect the abundance of A. muciniphila. To confirm this, studies taking both the microbial composition and mucus layer integrity into account should be performed. Altogether, these studies indicate the correlation of $A$. muciniphila to a healthy status and indicate the possible use of Akkermansia spp. as a biomarker for disease.

Interactions between the host and A. muciniphila have been studied in mice $[10,20]$. Colonization by $A$. muciniphila resulted in transcriptional changes, leading to an increase in the expression of genes associated with immune responses [20]. Furthermore, A. muciniphila was found to strengthen the gut barrier function in mice [10]. By doing so, A. muciniphila played a role in normalizing metabolic endotoxemia and adipose tissue metabolism. These findings have been supported by another study showing that $A$. muciniphila affects genes involved in cellular lipid metabolism [21]. The effect of a fiber-free diet was studied in mice colonized with a synthetic community consisting of 14 species, including A. muciniphila [22]. Feeding these mice a fiber-free diet was found to damage the mucus barrier. The changes in microbial community included an increased abundance of A. muciniphila and a switch in metabolism of gut microbiota species from fiber degradation to mucus glycan degradation [22,23]. An in vitro study using human colonic cell lines (Caco-2 and HT-29) demonstrated the adherence of $A$. muciniphila to the intestinal epithelium, thereby strengthening the epithelial integrity rather than causing a pro-inflammatory reaction [24]. Lastly, outer membrane proteins of A. muciniphila were found to have a role in the modulation of immune responses [25]. Recently, one of the outer membrane proteins was identified (Amuc_1100) [26]. This study demonstrated that the outer membrane pili-like protein is involved in immune regulation and the enhancement of trans-epithelial resistance.

Several studies have purposely or unintentionally revealed the presence of Akkermansia-like spp. in segments of the human body other than the colon, where A. muciniphila might also have important functions. In this review, we will discuss the presence of Verrucomicrobia and Akkermansia-like spp. in different anatomic regions of the digestive tract. The physiology and environmental parameters of these anatomic regions will be taken into account to assess the possibility of $A$. muciniphila to colonize and be active at these niches.

\section{Prevalence of Akkermansia muciniphila through Geography and Age in the Human Gastrointestinal Tract}

Akkermansia muciniphila is present in the intestinal tract throughout different stages of life $[27,28]$. This was determined using fecal samples from healthy subjects divided into groups based on their age, 
analyzed using fluorescence in situ hybridization (FISH) and quantitative PCR (qPCR). The number of bacteria related to $A$. muciniphila significantly increased from early life to adult subjects [27,28]. When focusing on the prevalence of bacteria related to $A$. muciniphila, $16 \%$ of one-month old infants in this study were found to harbor Akkermansia in their intestinal tracts [27]. At this very young age, the concentration of A. muciniphila ranged between 2.05 and $4.36 \mathrm{log}$ cells per gram of feces. Subsequently, at 6 months of age the percentage of infants where $A$. muciniphila could be detected increased to $72 \%$, with a further increase to $90 \%$ in 12-month-old infants. The concentrations were in the ranges of 2.50-7.30 and 2.80-9.50 $\log$ cells per gram of feces in 6-month-old and 12-month-old infants, respectively. However, in this study no correlation was made between the $A$. muciniphila abundance and the feeding mode of the infant (breast and/or formula feeding). Other studies not primarily focusing on the presence of $A$. muciniphila have also shown the presence of Akkermansia-like spp. or the Verrucomicrobia phylum in the infant's gut at different geographical locations, such as Finland, Germany, and Malawi [29-31]. The presence of $A$. muciniphila in the infant's gut could be considered as a marker for gut microbiota development and diversity [29]. Next to infants, adults (25-35 years old) were found to harbor 5-8.8 log cells per gram of feces of A. muciniphila, while a significant decrease was noted in elderly subjects (80-82 years old) namely, 95.5\% [27]. These outcomes differed in another study, where young adults harbored significantly less Akkermansia spp. than the elderly both in terms of prevalence and abundance [32]. In addition, centenarians were found to harbor a higher concentration of Akkermansia spp. Also, semi-supercentenarians (individuals with an age of 105 or higher) had a higher concentration of Akkermansia-like spp. than other (younger) age groups in the study [33]. A. muciniphila is proposed to have a role in the immunological and metabolic health of semi-supercentenarians, rendering it a biomarker for healthy aging. In contrast to age, gender does not play a role considering the amount of $A$. muciniphila [28].

The genome of A. muciniphila (ATCC BAA-835) was sequenced and annotated [12]. These sequences were used to mine 37 reported gastrointestinal tract (GIT) metagenomes derived from adults belonging to six nationalities to evaluate the presence and genetic diversity of Akkermansia spp. in the human gut. The prevalence of Akkermansia spp. in these metagenomes was found to be $30 \%$, using a cutoff of $>95 \%$ identity to $16 \mathrm{~S}$ rRNA. When queried with the Akkermansia genome (identity $>90 \%$ ), $62 \%$ of the metagenomic libraries were shown to be Akkermansia carriers, which is comparable to earlier findings of a Finnish cohort [27]. The relative abundances of Akkermansia spp. DNA in these libraries varied from $<0.01 \%$ to almost $4 \%$ [12]. However, higher abundances of Verrucomicrobia in the GIT have also been reported, for example in biopsy samples (up to $15 \%$ depending on the method and individual) [34]. The analysis of fecal samples from the Metagenomics of the Human Intestinal Tract (MetaHit) project, derived from Danish and Chinese individuals, revealed country-specific differences in gut microbiota [35]. In terms of Akkermansia-like spp., the mean relative abundance of Danish individuals (0.0137) was higher than that of Chinese individuals (0.0015). Moreover, a recent study showed that Verrucomicrobia sequences were found to be enriched in the guts of industrialized regions compared to the guts of traditional populations $\left(p<2 \times 10^{-16}\right)$, such as the traditional Hadza hunter-gatherers [36]. However, as with many comparative microbiota analyses, confounding factors related to sample processing, DNA extraction, and subsequent processing cannot be ruled out [37]. A study performed in China showed that the frequency of $A$. muciniphila is lower in southern Chinese than in European populations [38]. The frequency in southern China was found to be 51.71\%, which is significantly lower than the $\sim 75 \%$ found in European populations $[27,38]$. Interestingly, in southern China the highest frequencies were detected among the elderly, while in European populations a significant decrease was noted for the elderly. This observed difference may be due to external factors affecting the microbiota composition, including geographic location, diet, and age.

The human intestine may be colonized by different Akkermansia-like spp. [12]. The 16S rRNA sequences detected in metagenomic datasets suggested colonization by at least eight different Akkermansia-like spp. However, as these sequences derived from short Illumina reads, mis-assembly and other technical biases may have affected this conclusion. Moreover, it is also possible that simultaneous colonization by different species occurs. Recently, 39 A. muciniphila strains were isolated from human 
and mouse feces and subsequently analyzed for their 16S rRNA sequences and draft genomes [38,39]. All 16S rRNA sequences from these strains shared over 97\% sequence identity with that of the type strain A. muciniphila $\mathrm{Muc}^{\mathrm{T}}$ isolated from Europe, suggesting that they represent isolates from the same species. Using these isolates, three phylogroups (AmI, AmII, and AmIII) were identified based on core genome single nucleotide polymorphisms (SNPs). We constructed a maximum likelihood tree based on the available $16 \mathrm{~S}$ sequences of the Chinese $A$. muciniphila strains in the National Center for Biotechnology Information (NCBI) sequence database and all other 16S rRNA Akkermansia-like sequences derived from colonic and ileal biopsy samples derived from the SILVA small subunit Reference 132 dataset (Figure 1a and Supplementary Figure S1). In this tree, the newly isolated Chinese A. muciniphila strains fall into two out of three distinct clades (clades one and two) that, however, have only minimal differences. In comparison with the type strain, the first clade has 99-100\% identity, the second clade 98-99\%, and the third clade 98\%. Interestingly, the Chinese A. muciniphila strains have reportedly distinct metabolic and functional features [39]. However, unlike $A$. muciniphila-type strain $\mathrm{Muc}^{\mathrm{T}}$, complete closed genomes of these Chinese $A$. muciniphila strains have not been reported. Furthermore, functional analysis of the Chinese $A$. muciniphila strains has not been performed, but the strains are able to grow on mucus [39]. Next to A. muciniphila, only one other Akkermansia-like sp. has been validly described, namely Akkermansia glycaniphila strain $\mathrm{Pyt}^{\mathrm{T}}$ isolated from reticulated python feces (included in the phylogenetic tree shown in Figure 1a) $[40,41]$. The closest relative of $A$. glycaniphila is A. muciniphila Muc ${ }^{\mathrm{T}}$, sharing $94.4 \% 16 \mathrm{~S}$ rRNA sequence similarity [40]. The average nucleotide identity between the A. glycaniphila $\mathrm{Pyt}^{\mathrm{T}}$ genome and the genome of $A$. muciniphila $\mathrm{Muc}^{\mathrm{T}}$ was found to be $79.7 \%$. Compared to A. muciniphila, A. glycaniphila is also able to use mucin as a sole carbon, energy, and nitrogen source. However, the relatedness between these two species, determined by DNA-DNA hybridization, is low, namely $28.3 \%$. To be able to compare functional differences between Chinese A. muciniphila strains, the Akkermansia-like sequences found in biopsies of the ileum and large intestine (included in the tree), and A. muciniphila $\mathrm{Muc}^{\mathrm{T}}$, enclosed genomes and functional analyses are needed.

Altogether, $A$. muciniphila's presence varies among individuals. Its abundance varies not only from person to person but also from age group to age group. On top of that, other factors such as geographical location may also play an important role in the presence and richness of Akkermansia-like spp. in the human GIT.
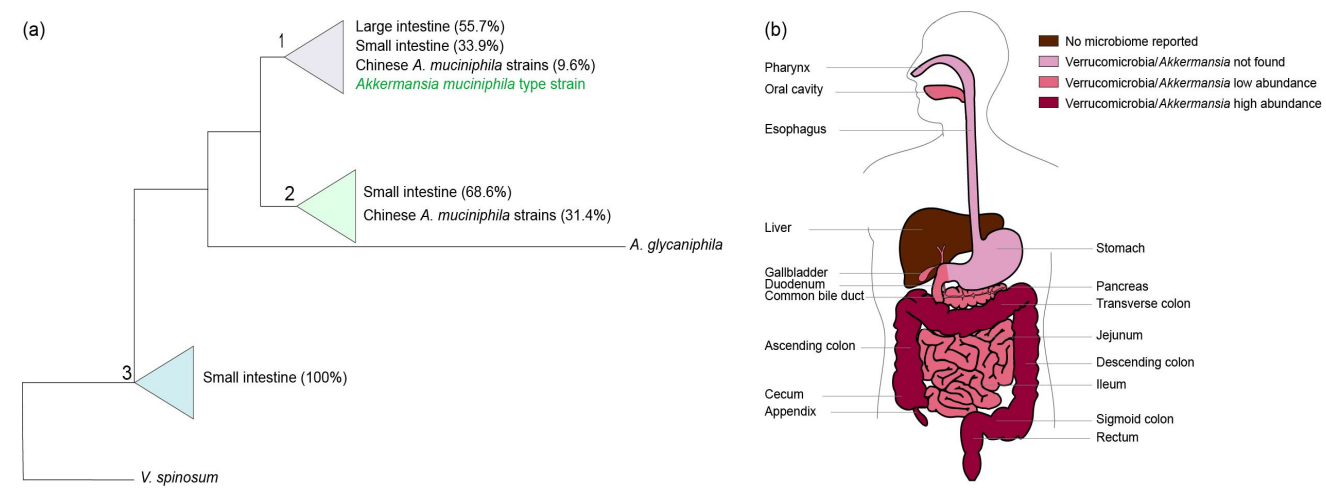

Figure 1. (a) Akkermansia is not only present in the large intestine, but also in other anatomic regions of the digestive tract. A schematic overview of the positioning of $16 \mathrm{~S}$ rRNA clones in the small and large intestines and the available sequences of the Chinese A. muciniphila strains towards the A. muciniphila-type strain $\mathrm{Muc}^{\mathrm{T}}$ and A. glycaniphila $\mathrm{Pyt}^{\mathrm{T}}$. The percentages indicate the compositions of the clades. The tree was generated using the randomized axelerated maximum likelihood (RAxML) method version 7.0.3 in ARB using a 40\% positional conservatory filter [42]. The original detailed maximum likelihood tree is shown in Supplementary Figure S1. Similar groups were observed using the neighbor joining method (Supplementary Figure S2). (b) Overview of Verrucomicrobia/Akkermansia sequences in the human digestive tract. 


\section{Physiologic Adaptation of Akkermansia muciniphila to the Human GIT}

A. muciniphila is an oval shaped, anaerobic Gram-negative bacterium that was first described by Derrien et al. [11]. Transmission electron microscopy revealed the presence of filamentous structures on $\mathrm{Muc}^{\mathrm{T}}$ cells when grown on mucin medium. On top of this, strain $\mathrm{Muc}^{\mathrm{T}}$ is able to exclude Indian ink, suggesting that the filamentous structures are capsular polymers. More recently, outer membrane proteins of $A$. muciniphila were analyzed, which resulted in the identification of pili proteins $[13,25,26]$.

When focusing on the growth parameters of A. muciniphila, it is known that growth was observed between temperatures of 20 and $40^{\circ} \mathrm{C}$ and $\mathrm{pH}$ values of 5.5-8.0 (Figure 2) [11]. However, the optimum growth temperature and $\mathrm{pH}$ are $37^{\circ} \mathrm{C}$ and 6.5, respectively. A. muciniphila is an obligate chemoorganotroph, utilizing mucus as a sole carbon, nitrogen, and energy source [11]. Consequently, the short chain fatty acids (SCFAs) acetate, propionate, and to smaller extent 1,2-propanediol and succinate are produced [11,43]. Another factor that influences the growth of A. muciniphila is the presence of oxygen. A. muciniphila was found to be able to tolerate and even benefit from nanomolar concentrations of oxygen in liquid medium [44]. Upon the presence of oxygen, there is a change of acetate to propionate production by A. muciniphila. This results in an increased production of ATP and $\mathrm{NADH}$, which enhances the growth of $A$. muciniphila.

To compose a minimal medium for A. muciniphila, a genome-scale metabolic model was constructed [43]. This model predicts the degradation of mucin-derived monosaccharides. The model showed that $A$. muciniphila is able to synthesize all essential amino acids, except for L-threonine, was not present in the pathway. Furthermore, growth experiments revealed that $A$. muciniphila can degrade a variety of sugars such as glucose, $N$-Acetylglucosamine (GlcNAc), $N$-Acetylgalactosamine (GalNAc), and fucose. However, to obtain growth large amounts of casein tryptone, mucin or a rich medium was required. Hereafter, another study showed that $A$. muciniphila does not code for GlmS, which mediates the conversion of fructose-6-phosphate to glucosamine-6-phosphate [45]. This reaction is essential for peptidoglycan formation. Therefore, the degradation of glucose does not lead to biomass production. A. muciniphila does code for $\mathrm{NagB}$, which catalyzes the reverse reaction, indicating that the addition of GlcNAc is essential for growth of $A$. muciniphila. Altogether, this information led to the development of a defined minimal medium for A. muciniphila, in which L-threonine and GlcNAc or GalNAc are essential components for growth [45].

Recently, the growth of $A$. muciniphila in the presence of bile has been studied [46]. Interestingly, the A. muciniphila abundance was positively correlated to circulating primary bile acids in mice [47]. The addition of $0.1 \%, 0.5 \%$, and $1 \%$ porcine bile extract resulted in increased growth of A. muciniphila in comparison to the medium that did not contain bile [46]. In contrast, purified bile salts addition of $0.5 \%$ or higher resulted in inhibited growth of $A$. muciniphila, whereas the addition of $0.1 \%$ purified bile salts did not inhibit growth [48]. Moreover, the survival of $A$. muciniphila in gastric juice was found to be very low [46].

Several studies have described the antibiotic resistance of $A$. muciniphila $[49,50]$. The type strain of $A$. muciniphila (Muc ${ }^{\mathrm{T}}$ ) was found to be susceptible to imipenem, piperacillin/tazobactam, and doxycycline, while resistance was noted for vancomycin, metronidazole, and penicillin G [49]. Another A. muciniphila strain was resistant against vancomycin and ofloxacin, but susceptible to penicillin, amoxicillin, ceftriaxone, and imipenem [50]. A. muciniphila MucT has potential beta-lactamase genes and may code for a 5-nitroimidazole antibiotic resistance protein [12]. The in silico prediction of a strain directly sequenced from stool (A. muciniphila strain Urmite) predicted the presence of antibiotic resistance genes for the classes beta-lactamases, glycopeptides, MLS (macrolides, lincosamides, streptogramines), phenicol, sulphonamide, tetracycline, and trimethoprim [51]. Guo et al. described the presence of three antibiotic resistance genes in A. muciniphila strain GP36, which originated from plasmid pRSF1010 (8684 bp) of Salmonella enterica [39]. This indicates that A. muciniphila might acquire antibiotic resistance genes through lateral gene transfer. 

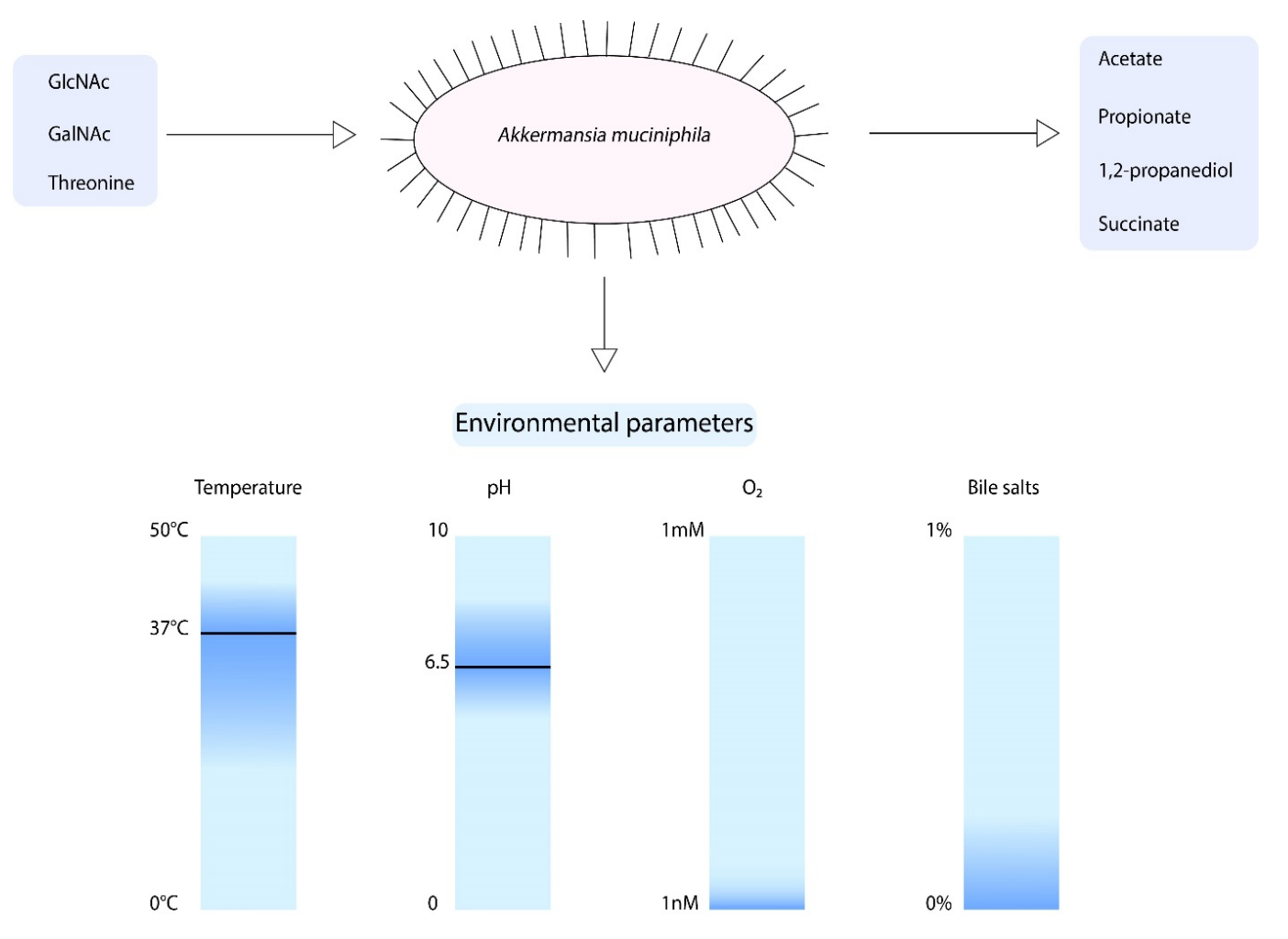

Figure 2. Schematic overview of the growth parameters of $A$. muciniphila. The optimum growth temperature and $\mathrm{pH}$ are $37^{\circ} \mathrm{C}$ and 6.5 , respectively. In addition, A. muciniphila is able to tolerate $\mathrm{nM}$ concentrations of oxygen and is able to grow in the presence of $0.1 \%$ purified bile salts.

The growth parameters of $A$. muciniphila described above coincide with the environmental parameters found in the large intestine. The oxygen concentration in the intestine follows a steep gradient from the intestinal submucosa to the lumen, where the oxygen concentrations decrease to near anoxia [52]. A. muciniphila may take advantage of this oxygen concentration in the mucus layer, enhancing its growth. The mucosal layer of the large intestines serves as a carbon, nitrogen, and energy source for the use of A. muciniphila. The mucin backbone is rich in threonine (among other amino acids) and contains many sugar groups, including GlcNAc and GalNAc [53]. As mentioned earlier, these are among the minimal growth requirements of $A$. muciniphila. Although the mucus layer in the large intestine is thought to be the optimal niche for A. muciniphila, mucus is also present at other locations of the GIT. Several conditions may vary in the GIT, such as type of mucin that is secreted, $\mathrm{pH}$, oxygen concentration, and concentration of bile acids. The ability of $A$. muciniphila to cope with these conditions will be discussed below.

\section{Akkermansia muciniphila along the Human Gastrointestinal Tract}

Akkermansia-like spp. were found to be present in different anatomical regions of the digestive tract, including the oral cavity, breast milk, pancreas, biliary system, small and large intestines, and appendix (Figure 1b). Next to the aforementioned regions, Akkermansia-like sequences were also detected in human blood [50,54,55]. However, the presence of Akkermansia-like sequences was only detected in subjects with diseases as septicemia and cirrhosis. In a mice study, A. muciniphila was detected in the oral cavity, stomach, small intestine, and large intestine the upon administration of breast milk and formula milk [56]. However, in this review we will mainly focus on the presence of Akkermansia-like spp. in the human body. 


\subsection{Oral Cavity}

The oral cavity is a moist environment with a relatively constant temperature between 34 and $36{ }^{\circ} \mathrm{C}$ [57]. There are several ecological niches in the oral cavity that mostly have a neutral $\mathrm{pH}$. The mean $\mathrm{pH}$ of the mucosal sites was found to be $6.78 \pm 0.04$ [58]. Examples of different sites in the oral cavity are the tongue, soft and hard palates, tooth surfaces, and tonsils [57]. In terms of temperature and $\mathrm{pH}$, the oral cavity can support the growth of a wide variety of microorganisms. Therefore, the microbial community of the oral cavity is site-specific and highly diverse [59].

Several studies found a high abundance of the phyla Firmicutes, Proteobacteria, Bacteroidetes, and Actinobacteria, with Streptococcus (belonging to the phylum Firmicutes) being the most abundant genus [60,61]. The presence of Verrucomicrobia in the oral cavity is often not described [60-64]. However, the presence of Akkermansia-like sequences was found in the oral cavity of a choledocholithiasis patient [65]. The salivary samples were taken by gargling with $20 \mathrm{~mL}$ of sterile saline water. Thus, the microorganisms in these samples originate from multiple niches in the oral cavity.

The relative abundance of Akkermansia-like spp. in this sample was low, namely $0.02 \%$ [65]. In addition, these sequences were only found in one out of six patients included in this study. In terms of $\mathrm{pH}$ and temperature, Akkermansia spp. could be able to survive in the oral cavity [11]. Furthermore, Gram-negative and obligate anaerobes with proteolytic lifestyles are present in healthy gingival crevice biofilms [66]. As discussed before, A. muciniphila has a mucin-degrading lifestyle [11]. The mucins found in the oral cavity are MUC5B, MUC7, MUC19, MUC1, and MUC4 [67]. Of these mucin structures, MUC5B is the most abundant gel-forming mucin in the oral cavity $[68,69]$. As A. muciniphila has mucin-degrading enzymes similar to those found in oral Streptococcus spp., A. muciniphila might be able to use the mucin structures in the oral cavity as a substrate for growth [70,71]. However, further research is needed to confirm this hypothesis.

Mucin oligosaccharides are able to bind microbes and in some cases exert functions in antimicrobial activity or carry antimicrobial proteins [67]. For example, MUC7 and MUC5B both bind statherin and histatin-1. By binding these molecules, mucins exert a protective function in the oral cavity. The potential role of Akkermansia spp. in the oral cavity is unknown. However, one could hypothesize that its capability to stimulate the mucus production of the epithelial cells enhances their protection e.g., against pathogens. Another possibility could be that Akkermansia spp. produces compounds in mucin degradation that could be useful for other bacteria in the oral microbial community. Lastly, Akkermansia spp. might be involved in the modulation of the host response. Altogether, more studies should be conducted to confirm the presence of Akkermansia spp. and its function in the oral cavity.

\subsection{Pancreas}

The pancreas is a complex organ comprised of both exocrine glands (secreting digestive enzymes into the intestinal lumen) and endocrine glands, called the islets of Langerhans, which secrete hormones directly into the bloodstream [72]. The pancreas plays a central role in human metabolism, allowing ingested food to be converted and used as fuel by cells throughout the body. The pancreas may be affected by devastating diseases, such as pancreatitis, pancreatic adenocarcinoma (PAC), and diabetes mellitus (DM), which generally results in a wide metabolic imbalance [73]. Nutrient metabolism in pancreatic cells is not only essential for providing energy for the cell, but also serves as a mechanism to sense and react to circulating levels of macronutrients. This gives the pancreas a central role in metabolism regulating the whole-body energy homeostasis. Efficient energy metabolism in pancreatic endocrine cells of the islets is required to permit the secretion of many hormones, mainly insulin and glucagon, that regulate glucose and lipid utilization throughout the body. The pancreas is thought to be devoid of bacteria. However, microbial translocation as a result of disease states has led to measurements of microbes in pancreatic tissue. Because it is dangerous and impossible to take biopsies of pancreatic tissue, due to the risk of leakage of pancreatic fluid, pancreatic samples can only be 
obtained via surgery. As such, samples of healthy individuals are not yet reported. Healthy controls are usually healthy tissue surrounding a pathologic site. Recent research has shown that disruption of pancreatic metabolism is often a consequence of disruptions in the gut microbiome [74]. Another study has shown that the $\mathrm{pH}$ in the pancreas drops significantly ( $p$-value $<0.05)$ in patients with painful chronic pancreatitis $(7.02 \pm 0.06)$ compared to healthy individuals $(7.25 \pm 0.04)$ [75]. That $\mathrm{pH}$ change in patients with chronic pancreatitis might be one of the reasons why the bacterial barrier in the pancreas is ruptured and the abundance of bacterial phyla and species is elevated [76].

A. muciniphila plays an important role in the maintenance of the gut barrier function [16]. A few studies have shown the association of $A$. muciniphila with the pancreas and its health. A recent study with patients undergoing pancreatic fluid pancreaticoduodenectomy (PD) revealed that the mean relative abundances of the Verrucomicrobia phylum and Akkermansia genus, respectively, were 0.0005 and 0.0004 in the pancreas of these patients [77]. The study also highlighted that in the pancreas tissue of the patients, other commensal bacteria were found to be present. The Proteobacteria phylum and Klebsiella genus were the most abundant, with mean relative abundances of 0.5410 and 0.2011 , respectively. Faecalibacterium, Bacteroides, and Prevotella were also detected in the pancreas of PD patients. The presence of other gut microbes in the pancreas apart from Akkermansia may indicate trophic interactions between them.

Interestingly, it was found that mice treated with pancreatic enzyme replacement therapy (PERT), had a significant, 58 -fold increase of $A$. muciniphila sequences compared to the control samples (mice treated with tap water) [78]. Furthermore, it is stated that pancrealipase diminishes pancreatic exocrine insufficiency-associated symptoms by inducing the colonization of A. muciniphila followed by the normalization of the intestinal barrier. Therefore, it is hard to speculate on the role of Akkermansia species and/or A. muciniphila in the pancreas.

The Akkermansia genus is detected in the pancreas, mainly in conditions of pathology. The significant change of $\mathrm{pH}$ of the pancreatic fluid in patients with chronic pancreatitis $(7.02 \pm 0.06)$ might be a reason why Akkermansia was detected in pathological conditions. Thus far, there is not any evidence showing that the pancreas is colonized by bacteria in healthy individuals or that it is a bacteria-free organ. In all of the studies that have been described so far, the bacterial colonization of the pancreas is inextricably linked to the cause of pancreatic disease. The higher abundance of bacteria in patients with pancreatic diseases could be associated with an overall higher abundance of microbiota members in these states of disease due to bacterial overgrowth and translocation. Decreased gut barrier function in both acute and chronic pancreatitis increases bacterial translocation. This bacterial translocation could have significant impact on the nutrient absorption and therefore on the availability of nutrients for intestinal microorganisms, and the microbial composition of the gut.

\subsection{Bile Ducts and Gallblader}

Bile is a complex aqueous solution secreted by the liver [79]. Both gallbladder bile and common bile duct bile of patients undergoing cholecystectomy were found to have an alkaline $\mathrm{pH}$ in the ranges of 6.8-7.65 and 7.5-8.05, respectively [80]. In most animal/mammal species, bile contains less than $5 \%$ solid contents [79]. The most abundant organic substances in bile are bile salts [81]. The primary bile salts in the mammalian liver are cholic acid and chenodeoxycholic acid (CDCA). They are produced from cholesterol in the liver and are then excreted into the duodenum [82]. Bile salts exert several functions. For example, they were found to have a role in antimicrobial defense, promoting lipid absorption and protein digestion and assimilation $[83,84]$. Conjugation of these bile salts occurs at the side chain, where either taurine or glycine is added, leading to the formation of stronger acids [81]. Intestinal bacteria are able to convert the stronger acids producing secondary bile acids by deconjugating them. Large amounts of bile salts are secreted into the intestine; however, only limited amounts are excreted from the human body [85]. More than $95 \%$ of the bile salts are reabsorbed in the ileum and redirected to the liver for recirculation. According to this enterohepatic circulation mechanism, each bile salt is recirculated approximately 20 times. 
Interestingly, the bile duct was first considered to be generally sterile [86]. However, more recently several studies have focused on the microbial community present in bile $[65,77,87-90]$. The phyla Firmicutes, Fusobacteria, Proteobacteria, Actinobacteria, and Bacteroidetes (among others), have been identified in bile samples $[65,77,88,89]$. These phyla are all commonly found in the human GI tract [91]. Subsequently, the bacteria found in the biliary tract are likely to originate from the human duodenum [65]. The most common genera in bile samples were found to be Prevotella, Streptococcus, Veillonella, Fusobacterium, and Haemophilus [89].

To study the function of the biliary microbiota, predictive functional profiles were constructed using Phylogenetic Investigation of Communities by Reconstruction of Unobserved States (PICRUSt) [65]. This method revealed that biliary bacteria have significantly enriched pathways, in comparison to the upper digestive tract microbiota, related to environmental information processing, cell motility, carbohydrate metabolism, amino acid metabolism, and lipid metabolism. Furthermore, several studies have focused on the role of the biliary microbiota in the development of diseases such as gallstone disease and biliary neoplasia in primary sclerosing cholangitis (PSC) $[88,89,92,93]$. However, to explore the exact role of the microbiota in gallstone formation, more research needs to be conducted. In addition, PSC was not associated with changes in the microbial community of the biliary system [89]. However, Streptococcus species were found to be positively correlated to disease progression and might therefore have a pathogenic role in the progression of PSC.

Although the presence of Verrucomicrobia and/or Akkermansia-like sequences has not been described in all studies involving the biliary microbiota, they have been found to be present in a proportion of studies including bile samples $[65,77,88,89]$. In a study describing the bacterial community in bile and gallstone samples, Akkermansia-like sequences were detected [88]. The relative abundance of Akkermansia-like sequences in 12 out of 26 bile samples ranged between 0.03 and $0.4 \%$. In addition, 10 out of 29 gallstone samples contained Akkermansia spp. with a relative abundance ranging between $0.02 \%$ and $0.3 \%$. Akkermansia-like sequences were also detected by another study in the bile sample of one out of six gallstone patients, revealed using V3-4 Illumina sequencing [65]. The relative abundance of Akkermansia-like sequences in this sample was low, namely $0.153 \%$. In addition, the mean relative abundances of Verrucomicrobia and Akkermansia spp. were determined to be $0.05 \%$ and $0.04 \%$, respectively, in bile samples from 50 patients undergoing pancreaticoduodenectomy [77]. Furthermore, bile samples of subjects with opisthorchiasis (bile duct infection by Opisthorchis felineus [94]) contained higher amounts of Verrucomicrobia (among other phyla) than subjects with gallstone disease without infection of O. felineus [93]. The presence of Verrucomicrobia was not specific to the Akkermansia genus and the exact relative abundance of Verrucomicrobia was not provided. Even though five phyla including Verrucomicrobia were found to be more abundant in infected subjects than non-infected subjects, there were no functional differences between these groups based on analysis using PICRUSt. The studies described in this section were properly controlled for contaminants.

The $\mathrm{pH}$ values of gallbladder bile and common bile duct bile are both within the growth range of A. muciniphila. However, for Akkermansia spp. to be able to remain in bile, they are expected to harbor a mechanism for protection against bile. A putative bile acid transporter gene (Amuc_0139) is annotated in the genome of $A$. muciniphila, which might function to export bile acids from the cell [48]. This process could reduce the effects of bile acids inside the cells of $A$. muciniphila. Another possible mechanism, as identified in Bifidobacterium spp., is the protection of the cell wall against bile acids by the production of exopolysaccharides $[95,96]$. However, this mechanism has not been identified for Akkermansia muciniphila.

Several mucins have been identified in the biliary tract, specifically in the gallbladder. The mucins that are expressed in the gallbladder are MUC3, MUC5B, MUC5AC, and MUC6 [97-100]. Even though colonic mucin consists mainly of MUC2, A. muciniphila might be able to use the mucins in the gallbladder as a substrate. Next to Akkermansia spp. other bacteria with mucin-degrading capacities in the GI tract have been identified in the biliary system. As such, Streptococcus anginosus [93] and 
bacteria with operational taxonomic unit (OTU) IDs with $99 \%$ identity matching that of Bacteroides vulgatus [88] were found to be present in bile samples. Although the function of Akkermansia spp. in the biliary system is unknown, it might have a role in the strengthening of the mucosal barrier. In this way, the mucosal layer may provide increased protection against pathogens. This could explain the increase of Verrucomicrobia during infection of Opisthorchis felineus, since it might function to strengthen the mucosal barrier and thereby provide protection during infection.

\subsection{Small Intestine}

The GIT supplies the human body with energy and essential nutrients [101]. This is achieved by the conversion and absorption of food components reaching the small intestine. The small intestine can be divided into three segments: duodenum, jejunum, and ileum [102]. The transit time of the small intestine was found to be between $30 \mathrm{~min}$ and $4.5 \mathrm{~h}$ [103]. Once the gastric content enters the duodenum, it is neutralized by bicarbonate derived from the pancreas, liver, and duodenal mucosa, causing $\mathrm{pH}$ fluctuations [104]. More recent investigations of $\mathrm{pH}$ profiles revealed that $\mathrm{pH}$ values increased from 5.9-6.3 in the proximal part of the small intestine (duodenum) [105]. In the distal parts, $\mathrm{pH}$ values were found to increase to $\mathrm{pH}$ 7.4-7.8.

The epithelial cells within the small intestine are covered with mucus. In contrast to the mucosal layer in the stomach and the colon, the mucosal layer in the small intestine is thinner and less dense [106]. In addition, this layer is not firmly attached to the epithelial surface and forms a soluble mucus gel $[106,107]$. The mucus gel layers observed in the duodenum and jejunum are similar in thickness, although no loose/sloppy mucus was found in the jejunum [106]. In contrast to the duodenum and jejunum, the mucus layer in the ileum is significantly thicker. The accumulation rates were similar throughout the different segments of the small intestine.

The fast transit time, in comparison to the large intestine, contributes to limited microbial growth in the small intestine [102]. In addition, the secretion of digestive enzymes and bile into the small intestine creates a harsh environment in terms of microbial growth [101]. The bacterial concentration in the duodenum and jejunum is only $10^{3}-10^{4}$ bacteria $/ \mathrm{mL}$ content [108]. This concentration increases in the ileum, where the bacterial concentration is $10^{8}$ bacteria $/ \mathrm{mL}$ content. Due to the challenging conditions for microbial growth in the small intestine (acidity and higher oxygen levels than in the colon), the microbial community is dominated by bacteria that are facultative anaerobic, able to grow quickly, and able to tolerate bile acids and antimicrobials [109]. At the same time, these bacteria are also competing with the host and other microorganisms for simple sugars in the small intestine. Interestingly, phagocytes in the small intestine are thought to play a role in immune surveillance of the small intestinal mucosa [110]. This means that phagocytes are able to selectively take up bacteria, which might be linked to maintaining immune homeostasis.

The location of the small intestine in the human body causes difficulties in sampling, in comparison to, for example, the oral and fecal microbiota. Therefore, fewer studies have been performed describing the microbiota in the small intestine [101,111]. In the duodenum, the phyla Firmicutes and Actinobacteria were found to be predominant in the duodenal fluid of both obese and healthy groups ( $n=5$ for each group) [112]. Other (less abundant) phyla detected in the duodenum were Proteobacteria, Fusobacteria, TM7, Bacteroidetes, and Tenericutes. However, an inter-individual variability in the taxonomic composition between these samples was observed. Even though the duodenum was found to have fewer OTUs than mouth, colon, and stool samples, it does harbor most phyla observed in the other sites [91]. The mucosa-associated microbiota of the duodenum was found to be dominated by the phylum Firmicutes and genus Streptococcus [113]. The genera Prevotella, Veillonella, and Neisseria were also found to be present in the mucosal layer. Interestingly, the duodenal mucosa-associated microbiota found in this study overlaps in broader levels of classification with that of the oral cavity and saliva. Further down the small intestine, the most dominant phyla in jejunal fluid were found to be Firmicutes, Proteobacteria, and Bacteroidetes [111]. Less abundant phyla (5-10\%) were Actinobacteria and Fusobacteria. In comparison to the findings of the microbiota composition in 
the duodenum, the abundance of Proteobacteria and Bacteroidetes were found to be dominant over Actinobacteria in the jejunum [111]. When comparing the microbiota composition found in samples obtained after the washing procedure and mucosal biopsies, these compositions were highly similar. The last part of the small intestine (ileum) was found to be dominated by the phyla Bacteroidetes, Clostridium cluster XIVa, and Proteobacteria [101,114].

Several studies have focused on the small intestinal microbiota in disease states, such as IBS, Crohn's disease, and liver cirrhosis [115-119]. A study focused on IBS showed that the small intestinal microbiota of IBS patients and healthy individuals did not differ in terms of major phyla or genera [117]. In contrast, the duodenal mucosal microbiota of cirrhotic patients were surprisingly different to that of healthy controls [118]. The dysbiosis observed in duodenal samples of cirrhotic patients might be associated with an altered oral microbiota or an altered environment of the duodenum.

Even though the phylum Verrucomicrobia is not included in the dominant microbial compositions described above, Verrucomicrobia and Akkermansia-like spp. have been detected in all segments of the small intestinal tract. In duodenal fluid, Verrucomicrobia and Akkermansia-like spp. were found in three out of six subjects (with relative abundances of $0.17 \%, 0.012 \%$, and $0.013 \%$ ) using V3-4 Illumina sequencing [65]. In addition, Verrucomicrobia (not specified to Akkermansia) were detected in duodenal biopsies $(0.0688 \%)$ and mucus $(0.0387 \%)$ using $454 /$ Roche GS FLX sequencing [120]. Jejunal contents have also been shown to harbor Akkermansia-like spp., with a mean relative abundance of $0.01 \%$ $(n=17)$ [77]. Analysis of swabs from jejunal contents were performed using Illumina MiSeq. Another study detected Akkermansia-like spp. in four out of 20 subjects with concentrations ranging from three to 90 hits, equaling to 0 to $0.029 \%$ of total hits, also using Illumina MiSeq [77]. Furthermore, Verrucomicrobia were found in the distal ileum using direct cloning and sequencing, making up 5\% of the detected microbial community [121]. Lastly, Akkermansia-like sequences were detected in the ileocecal biopsies of patients with PSC and ulcerative colitis, as well as non-inflammatory controls (relative abundances of $0.49 \% \pm 0.52 \%, 0.37 \% \pm 0.37 \%$, and $0.36 \% \pm 0.31 \%$, respectively) [122]. In the schematic tree in Figure 1a, the A. muciniphila sequences derived from ileum biopsies are clustered together. This occurs in particular in the third clade, which is made up entirely of Akkermansia-like sequences derived from the ileum, with a $16 \mathrm{~S}$ rRNA sequence identity of $98 \%$ in comparison to A. muciniphila $\mathrm{Muc}^{\mathrm{T}}$. The isolation of Akkermansia-like species in the ileum is needed to study possible differences between the strains found in the small intestine and the strains in the large intestine. Considering the $\mathrm{pH}$ in the small intestine, the Akkermansia-like spp. found in the ileum and other parts of the small intestine could have a different optimum $\mathrm{pH}$ for growth.

The function of the small intestinal microbiota was also studied using comparative metagenomics and RNAseq [101]. This study, in which A. muciniphila was not detected, revealed that the metabolic focus small intestinal microbiota lies within carbohydrate uptake and metabolism. In more detail, simple carbohydrate transport phosphotransferase systems, fermentation, central metabolism, the metabolism of amino acids, and the production of cofactors were enriched. A more recent study emphasized that the ileum mucosal microbiota might have a role in plant cell wall polysaccharide (PCW) degradation [123]. A large portion of the glycans that reach the small intestine are PCW polysaccharides. These polysaccharides cannot be degraded by humans, whereas the ileal microbiota associated with the mucus layer was found to have the enzymatic potential to break down PCW polysaccharides. The exact role of $A$. muciniphila in the small intestine remains unknown, but Akkermansia-like spp. could have a role in immune signaling in this part of the GIT. In mice, the addition of $A$. muciniphila in comparison with germ-free mice resulted in more significant modulation in the ileum of PPAR $\alpha-R X R \alpha$ activation, tryptophan metabolism, serotonin receptor signaling, and dopamine receptor signaling, among others [20]. The number of differentially expressed genes in the ileum of A. muciniphila mono-associated mice was 253 (144 upregulated and 99 downregulated genes). The administration of $A$. muciniphila resulted in an increase of Reg3g expression under the control diet and a decrease of Lyz1 expression in the ileum [10]. Another study also showed a decrease in Cnr1 expression and increase of Cldn3 expression in the ileum upon the administration of 
A. muciniphila in mice [124]. As discussed before, the mucus layer in the small intestine is thinner and less dense than that of the colon [106]. This allows closer contact between the microbial community and host cells, promoting immune signaling in this region of the gastrointestinal tract. The presence of Akkermansia-like spp. in the ileum might contribute to immune health.

\subsection{Large Intestine}

The large intestine specializes in digestion and consists of several different segments, namely the cecum, ascending colon, transverse colon, descending colon, rectum, and anus [125]. The colonic transit time of healthy individuals is longer than the transit time of the small intestine, ranging between 9 and $46 \mathrm{~h}$ (mean $28 \mathrm{~h}$ ) [126]. In healthy individuals, a decrease in luminal $\mathrm{pH}$ is observed in the cecum in almost all subjects ( $\mathrm{pH}$ ranging from 5.5-7.5) [127]. This drop in $\mathrm{pH}$ is due to the fermentation of carbohydrates by colonic bacteria, leading to the production of SCFAs. Then, the $\mathrm{pH}$ increases along the large intestines to $\mathrm{pH}$ values ranging between 6.1 and 7.5. The mucosal $\mathrm{pH}$ of the large intestine parallels the luminal $\mathrm{pH}$ [128]. However, the mucosal $\mathrm{pH}$ is less acidic than the luminal $\mathrm{pH}$ in all anatomic regions of the large intestine.

The epithelial cells along the large intestine are covered by the mucosal layer [129]. As such, the mucosal layer protects the epithelial cells from direct contact with microorganisms. On top of this, the mucosal layer also contains antimicrobial proteins such as IgA. The mucosal layer can be divided into two parts: the inner and outer mucus layers. The inner mucus layer is firmly attached to the epithelial cells and devoid of bacteria, whereas microbes are capable of colonizing the outer layer due to its higher permeability [107]. Both layers are mainly composed of the gel-forming mucin MUC2, consisting of large polymers that are formed by $\mathrm{N}$-terminal trimerization and C-terminal dimerization [130]. The expansion of the mucus layer occurs due to increased $\mathrm{pH}$ and decreased calcium $\left(\mathrm{Ca}^{2+}\right)$ levels. $\mathrm{N}$-terminal interactions are weakened by the decreased calcium concentrations. Therefore, water is able to bind to the mucin domain glycans, leading to the formation of flat mucin sheets. Furthermore, the less dense outer layer is the result of endogenous proteases, promoting the possibility of microbes to colonize the mucus layer [107]. The degradation of these mucins by mucin-degrading bacteria of the colon microbiota affects the host cells e.g., by producing SCFAs [131].

The gut microbiota is mainly studied using fecal samples, since these samples can be obtained without colonoscopies. However, microbial communities detected in fecal samples mainly reflect the luminal microbiota in the distal large intestine. Therefore, the microbial communities in biopsies can differ distinctly from that in fecal samples [91]. Several studies have confirmed that the microbial communities in biopsy samples of different anatomic regions of the colon show similarities, focusing on the major phylogenetic groups [91,121,132]. Along the intestinal tract, Firmicutes and Bacteroidetes were predominant, with lower proportions of Proteobacteria and Fusobacteria observed in biopsy samples [91,132]. The sequencing of fecal samples of 22 individuals from four different European countries revealed the presence of three robust clusters, called enterotypes [133]. These enterotypes are either enriched in (1) Bacteroides; (2) Prevotella and co-occurring Desulvibrio; or (3) Ruminococcus and co-occurring Akkermansia. Recently, a method of restricting enterotyping space was proposed to increase the ability to detect samples outside of these enterotyping spaces [134]. Overall, the dominant phyla in fecal samples derived from healthy individuals were found to be Firmicutes, Bacteroidetes, and Actinobacteria. Less abundant phyla were Proteobacteria and Verrucomicrobia [133].

In addition to studies on the role of the gut microbiota in health, the gut microbiota has also been studied in diseases such as IBD, IBS, obesity, and type-2 diabetes. A shift in microbiota composition was observed in IBD patients and may have a role in the onset, maintenance, and severity of the disease, although this shift could also partly be due to the disturbed gut environment [135]. In IBS patients, a decrease in bacterial diversity was observed $[136,137]$. However, a consistent gut microbiota pattern in IBS patients is lacking [138]. In obesity, inconsistent findings have been reported. For example, one study reported an increase of Firmicutes and a decrease of Bacteroidetes, while another reported the opposite $[139,140]$. Lastly, a decrease in canonical butyrate-producing bacteria was found in 
patients with T2D [141]. A decrease in butyrate-producing bacteria was associated with an increase in opportunistic pathogens, mainly Proteobacteria. Taken together, the studies on the gut microbiota in individual diseases are not all uniform, highlighting the difficulties in appointing markers for disease.

The gut microbiota plays an important role in the metabolism of host nutrients and the health maintenance of the host. Carbohydrates (mainly polysaccharides) that have not been hydrolyzed in the small intestine become available for the microbial community in the colon [142]. The main substrates entering the colon are resistant starch and polysaccharides derived from plant cell walls. The major end products produced by the gut microbiota are SCFAs (e.g., acetate, propionate, and butyrate) and gases (e.g., $\mathrm{H}_{2}$ and $\mathrm{CO}_{2}$ ) using the available substrates. Of these, butyrate is used as an energy source by colonic epithelial cells [143]. Furthermore, propionate is able to signal to the host through the GPR41 and GPR43 receptors [144]. Interestingly, SCFAs activate free fatty acid (FFA) receptor 2 and FFA3 in the gut [144-146]. These receptors control peptides (peptide YY and glucagon-like peptide 1) involved in appetite regulation [147]. Therefore, SCFA production in the gut may be associated with food intake. Next to dietary carbohydrates, the colonic microbiota also has a role in the degradation of host-derived glycans (mucin), xenobiotics, and drugs [142,148]. The gut microbiota is also able to stimulate host immunity in order to protect the host against pathogens [149]. In this way, the gut microbiota enhances the innate immune response and has a role in increasing the gut barrier function. One of the microbial species in the gut involved in immune regulation and increasing gut barrier function is A. muciniphila [10,26].

A recent study revealed the presence of Verrucomicrobiae in all anatomical regions of the large intestine by sequencing the V2 region [34]. The concentrations of Verrucomicrobiae (in two individuals) ranged between $0.3 \%$ and $15.8 \%$. Interestingly, one individual harbored only low concentrations, ranging between $0.3 \%$ and $1.4 \%$, while concentrations in another individual ranged between $9.8 \%$ and $15.8 \%$ throughout the anatomic regions. Notably, the individual with higher Verrucomicrobiae concentrations was a Crohn's disease patient. Differences were not only observed between individuals, but also between the experimental designs. The use of another DNA extraction method resulted in lower amounts of Verrucomicrobiae with concentrations in the range of $0.3-7.3 \%$ in both individuals. Next to this study, there are more studies identifying the Verrucomicrobia phylum and/or Akkermansia-like spp. focusing on several anatomic regions of the large intestine [91,121,150-153]. Verrucomicrobia were identified in the cecum by another study, although quantities were not shown [150]. Even though the $\mathrm{pH}$ is lower in the cecum ( $\mathrm{pH}$ 5.5-7.5), it is still within the growth range of $A$. muciniphila. In the ascending colon, Verrucomicrobia were identified with a concentration of $6 \%$ in the large intestine of a healthy volunteer [121]. Using a qPCR approach within the same region, a concentration of $4.17 \pm 0.6 \log 10$ genomes per gram of a sample of Akkermansia-like spp. was described [151]. Furthermore, the transverse colon of two out of four included subjects showed the presence of Verrucomicrobia, with 563 and 7771 sequence counts of this phylum in each sample [91]. In the sigmoid colon, compared to the transverse colon, the same study reported a decrease in one of the subjects (from 563 to 64 sequence counts), whereas an increase was noted in another subject (from 7771 to 11,941 sequence counts). The qPCR approach resulted in a similar concentration to that found in the ascending colon, namely $4.16 \pm 0.56 \log 10$ genomes per gram of a sample [151]. Several studies have also described the presence of Akkermansia-like sequences in the rectum $[91,121,152]$. Where one study reported a higher concentration in the rectum (9\%) than in the ascending colon, another reported a rapid decrease in sequence counts from 64 and 11,941 in the sigmoid colon, to sequence counts of 1 and 2, respectively [91,121]. In conclusion, based on these studies, the presence and abundance of $A$. muciniphila in the large intestine is subject-specific.

To compare the 16S rRNA Akkermansia-like sequences in biopsies to fecal samples, a maximum likelihood tree was constructed (Figure S3). Interestingly, the majority of the Akkermansia-like sequences derived from biopsies were clustered together. This cluster contains a low amount of Akkermansia-like sequences derived from fecal samples. Therefore, one could hypothesize that sub-populations of 
Akkermansia spp. exist within the large intestine. However, it should be noted that complete Akkermansia spp. genomes derived from biopsies and lumen are needed to support this hypothesis.

In contrast to the presence of $A$. muciniphila in other regions of the GIT, its function has been more explored in its ecological niche. A. muciniphila was found to be correlated to health and inversely correlated to several disease states (as explained in the introduction). However, besides its presence in health and disease, A. muciniphila was also found to be involved in syntrophic interactions [154]. For example, co-cultivations of $A$. muciniphila with butyrate-producing bacteria (Anaerostipes caccae, Eubacterium hallii, and Faecalibacterium prausnitzii) resulted in butyrate production. Therefore, it is suggested that the mucus-degrading capacity of $A$. muciniphila stimulates intestinal metabolite pool and specifically butyrate levels, which is beneficial for the host. Another example is the release of sulfate during mucin degradation. This sulfate might be used by sulfate-reducing bacteria in the colon, producing hydrogen sulfide $[155,156]$. In turn, A. muciniphila predictively harbors genes involved in L-cysteine biosynthesis using hydrogen sulfide, suggesting that $A$. muciniphila might have a role in the detoxification of hydrogen sulfide in the intestines [157].

As mentioned earlier, the colonization of $A$. muciniphila in mice led to an increased expression of genes associated with immune responses and the strengthening of the gut barrier function [10,20]. In addition, the outer membrane protein (Amuc_1100) was found to be involved in immune regulation and the enhancement of trans-epithelial resistance [26]. Altogether, these studies suggest an important role of A. muciniphila in the microbial community of the large intestine in addition to its role in host interactions, promoting the use of this bacterium as a therapeutic agent for intestinal disorders.

\subsection{Appendix}

The human appendix extends from the cecum and is $5-10 \mathrm{~cm}$ long and $0.5-1 \mathrm{~cm}$ wide [158]. The function of the appendix has been up for debate for quite some time. Charles Darwin described the lack of function of the appendix and noted that the appendix is a remainder from primate ancestors that ingested leaves, in which the appendix functioned to ferment plant material $[159,160]$. The appendix is covered in gut-associated lymphoid tissue, suggesting its involvement in immune function [161]. An apparent function of the human appendix was described, suggesting that the appendix functions as a "safe house" for beneficial bacteria [158]. This same study revealed a higher abundance of microbial biofilms in the appendix than other areas of the human colon. To our knowledge, a description of the $\mathrm{pH}$ in the human appendix is lacking. However, the rabbit appendix was found to have a $\mathrm{pH}$ ranging between 6.2 and 6.7 [162]. Secretions of the rabbit appendix are rich in bicarbonate and occur spontaneously and at a relatively rapid rate $(1-12 \mathrm{~mL} / \mathrm{h})$. Therefore, it has been suggested that in rabbits, the appendix may have a major role in the regulation of $\mathrm{pH}$ in the cecum. However, similar data is not available for the human appendix.

Considering the difficulty of obtaining samples of the human appendix, there are few studies describing the microbiota of the appendix. These studies mainly focus on the microbiota in appendicitis in comparison to healthy controls [163-165]. In healthy controls, the taxa Fusibacter, Selenomonas, and Peptostreptococcus were increased in comparison to the rectal microbiota [164]. This finding indicates that the human appendix harbors a distinct microbiota. A wide variation of abundances in phylum, genus, and species levels was detected within groups divided by health and severity of inflammation [165]. In healthy controls, Firmicutes and Bacteroidetes were found to be the most abundant phyla. Other abundant phyla detected in these samples were Fusobacteria, Actinobacteria, and Proteobacteria. Phyla with lesser abundances $(<2 \%)$ were Spirochaetes, Cyanobacteria, Synergistetes, Tenericutes, and Verrucomicrobia.

While some studies found significant differences between the microbiota of appendicitis patients and healthy controls [163,164] or between severity of inflammation [166], another did not [165]. One of the genera linked to appendicitis is Fusobacterium $[163,166]$. Increased abundances of this genus were observed in appendicitis patients in comparison to healthy controls [163], and the presence of Fusobacterium could be linked to the severity of inflammation [166]. In contrast, the 
presence of A. muciniphila was found to be inversely correlated to the severity of appendicitis [14]. Using fluorescence in situ hybridization (FISH), the mean proportion of single bacterial groups for A. muciniphila was found to be $4.0 \pm 4.6,1.0 \pm 2.1$, and $0.2 \pm-0.6$ for no appendicitis, catarrhal appendicitis, and suppurative appendicitis, respectively.

The mucus layer of the appendix was found to contain a more concentrated biofilm than other parts of the large bowel [158]. Therefore, the appendix might be a favorable niche for mucin-degrading bacteria, including A. muciniphila. Although the role of A. muciniphila in the appendix is not specified, one could hypothesize that, being part of the appendiceal microbiota, A. muciniphila might have a role in re-colonizing the colon after an infection or colonic dysfunction. Thereby, A. muciniphila could function in the maintenance of a healthy gut microbiota by restoring the mucus barrier function subsequent to infection/inflammation.

\subsection{Human Breast Milk and Early Life Intestine}

In breast-fed infants, the main source of glycans are human milk oligosaccharides (HMOs) [167]. Human milk consists of a mixture of nutrients for infants, conveying immunologic and other health benefits [147]. Human milk contains 5-15 g/L HMOs, and over 200 different HMO structures exist. The major monosaccharides present in HMOs are D-glucose, D-galactose, $\mathrm{N}$-acetyl-glucosamine, L-fucose, and $\mathrm{N}$-acetylneuraminic acid (sialic acid) [168]. HMOs in the infant gut act as substrates for specific bacteria in the gastrointestinal tract, functioning as natural prebiotics by stimulating the growth of beneficial intestinal bacteria such as bifidobacteria and lactobacilli [168,169]. It is remarkable to mention that milk oligosaccharides and glycoconjugates are able to prevent the development of pathogens and toxins, inhibiting their binding on the surface of the epithelial cells [170]. The structure of HMOs has chemical similarities to mucus glycans [171].

A. muciniphila has been identified in human milk samples immediately after delivery (colostrum), and at 1 and 6 months [172]. A. muciniphila cell counts in breast milk were measured after conducting qPCR, revealing that $A$. muciniphila was higher in abundance in overweight than normal weight mothers, with mean concentrations of 1.25, 1.09, and 1.20 log number of gene copies/ $\mathrm{mL}$ in colostrum samples and breast milk samples. Furthermore, A. muciniphila was observed to be present in colostrum samples that were collected from 11 women after elective caesarean with a median counts number of 0.9 (interquartile range from 0.0 to 1.5) analyzed by qPCR [173]. In turn, in samples from human breast tissue from 43 women (aged 18 to 90 years), the presence of Akkermansia-like species was found using 16S rRNA sequencing [174].

As mentioned earlier, A. muciniphila is also present in infants' intestines from the first months of life $[27,29,30]$. The structures in HMOs can also be found in mucus glycans $[175,176]$. A. muciniphila was able to break down structures of HMOs into simpler sugars, releasing SCFAs (acetate and propionate) in the media. A. muciniphila expressed enzymes that were involved in carbohydrate and glycan degradation, such as $\alpha$-L-fucosidases, exo- $\alpha$-sialidases, $\beta$-galactosidases, and $\beta$-hexosaminidases [177]. This indicates that $A$. muciniphila might be able to use HMOs, using human milk as a sole energy, carbon, and nitrogen source, which could also explain its presence in breast milk and the breast tissue of lactating woman.

To confirm this, further research should be conducted to gain more insight in the mucolytic activities and the function of $A$. muciniphila in human milk. The presence of Akkermansia spp. and A. muciniphila specific in human milk may benefit the maturation of the infant's microbiota establishment and immune maturation, as its outer protein was found to be involved in immune regulation [26]. Last but not least, $A$. muciniphila glycan degradation ability might be proved to play an important role in the initial colonization of the infant's gut, thus having a major impact on later life.

\subsection{Akkermansia Muciniphila in In Vitro Gut Models}

In contrast to invasive sampling of the human body, in vitro models have also been introduced to study the spatial organization of the human gut microbiota. Multiple in vitro models are available 
for this purpose, such as the Gastro-Intestinal Model (TIM-1 and TIM-2) and the Simulator of Human Intestinal Microbial Ecosystem (SHIME). The small intestinal model TIM-1 consists of four compartments representing the stomach, duodenum, jejunum, and ileum [178], while TIM-2 simulates the large intestine [179]. The SHIME was developed in 1993 [180]. This model simulates five compartments of the digestive tract, namely the stomach, small intestine, and the ascending, transverse, and descending colon. In addition, a variation on SHIME was developed, named the mucosal SHIME (M-SHIME) [181]. The M-SHIME has a mucosal compartment, developed to study the microbial colonization of the mucus layer.

Most of the studies including A. muciniphila used the SHIME model. The presence of A. muciniphila in different compartments of in vitro models has also been evaluated [182,183]. In SHIME, Akkermansia spp. are more abundantly present in the transverse and descending colon compartments than in the proximal compartments (ascending colon) of this model [182-185]. This is not in concordance with findings using biopsy samples, where no clear depletion of Verrucomicrobiae was observed in the ascending colon [34]. Another SHIME experiment also described the distal location of Akkermansia spp. [184]. In addition, in this model the growth of Akkermansia-like spp. was stimulated by black tea and red wine grape extract. Interestingly, in M-SHIME, A. muciniphila did not reach high densities as was observed in the distal compartments in the SHIME setup [186]. This might be due to the setup of the M-SHIME model, which is lacking distal colon compartments, where Akkermansia-like spp. reached the highest densities [182,184,185]. Recently, a study using the SHIME model demonstrated that A. muciniphila is $\mathrm{pH}$ - and mucin-dependent [183]. An increase of A. muciniphila was observed upon the addition of mucin. When the $\mathrm{pH}$ in the distal colon was lowered, a decrease in A. muciniphila was observed in comparison to the same compartment with a higher $\mathrm{pH}$. Altogether, these studies suggest that these models can be used to study the effect of environmental parameters and diet on the human gut microbiota in health and disease states.

\section{Conclusions}

To date, the presence of $A$. muciniphila has mainly been associated with the mucus layer of the colon. However, in this review we collected results from other studies and showed that Akkermansia-like sequences have also been found to be present in other anatomical regions of the digestive tract and human breast milk. In short, these regions are the oral cavity, pancreas, bile ducts and gallbladder, small intestine, large intestine, and appendix (Figure 1b). The environmental parameters (e.g., pH, oxygen and nutrient availability) differ among anatomic regions of the human body, affecting the growth of A. muciniphila. As the aforementioned organs have different functions, the function of A. muciniphila might also differ in different regions of the digestive tract. In this review, we proposed hypothetical functions of $A$. muciniphila in these regions; however, further research is needed to confirm its role among the different regions of the digestive tract. Altogether, the presence of Akkermansia-like spp. along the digestive tract indicates that this bacterium might have more functions than those known so far. Still, as can be concluded from abundance of Akkermansia-like spp., its optimal ecological niche remains the mucus layer in the colon.

Supplementary Materials: The following are available online at http:/ / www.mdpi.com/2076-2607/6/3/75/s1: Figure S1: Detailed maximum likelihood phylogenetic tree (RAxML) including Akkermansia-like sequences derived from large intestine and ileum biopsies and Chinese A. muciniphila strains; Figure S2: Detailed Neighbor Joining phylogenetic tree including Akkermansia-like sequences derived from large intestine and ileum biopsies and Chinese A. muciniphila strains; Figure S3: Detailed maximum likelihood phylogenetic tree (RAxML) including Akkermansia-like sequences derived from fecal samples, large intestine, and ileum biopsies and Chinese A. muciniphila strains.

Author Contributions: S.Y.G., W.M.d.V., and C.B. defined the topic of the review. S.Y.G. and I.K. wrote the manuscript. C.B. guided the writing of this manuscript. C.B. and W.M.d.V. provided their input and critically reviewed the manuscript.

Funding: The work was supported by the Netherlands Organization for Scientific Research (SIAM Gravity Grant 024.002.002) and the EU Joint Programming Initiative-A Healthy Diet for a Healthy Life (JPI HDHL, http:/ / www.healthydietforhealthylife.eu). 
Acknowledgments: We would like to thank Asimenia Gavriilidou and Daan van Vliet, who provided insight and expertise in the phylogenetic analysis.

Conflicts of Interest: The authors declare no conflict of interest.

\section{References}

1. Blaser, M.J. The microbiome revolution. J. Clin. Investig. 2014, 124, 4162-4165. [CrossRef] [PubMed]

2. Verdu, E.F.; Galipeau, H.J.; Jabri, B. Novel players in coeliac disease pathogenesis: Role of the gut microbiota. Nat. Rev. Gastroenterol. Hepatol. 2015, 12, 497-506. [CrossRef] [PubMed]

3. Distrutti, E.; Monaldi, L.; Ricci, P.; Fiorucci, S. Gut microbiota role in irritable bowel syndrome: New therapeutic strategies. World J. Gastroenterol. 2016, 22, 2219-2241. [CrossRef] [PubMed]

4. $\quad$ Lopez-Siles, M.; Martinez-Medina, M.; Busquets, D.; Sabat-Mir, M.; Duncan, S.H.; Flint, H.J.; Aldeguer, X.; Garcia-Gil, L.J. Mucosa-associated Faecalibacterium prausnitzii and Escherichia coli co-abundance can distinguish Irritable Bowel Syndrome and Inflammatory Bowel Disease phenotypes. Int. J. Med. Microbiol. 2014, 304, 464-475. [CrossRef] [PubMed]

5. Sheehan, D.; Moran, C.; Shanahan, F. The microbiota in inflammatory bowel disease. J. Gastroenterol. 2015, 50, 495-507. [CrossRef] [PubMed]

6. Png, C.W.; Linden, S.K.; Gilshenan, K.S.; Zoetendal, E.G.; McSweeney, C.S.; Sly, L.I.; McGuckin, M.A.; Florin, T.H. Mucolytic bacteria with increased prevalence in IBD mucosa augment in vitro utilization of mucin by other bacteria. Am. J. Gastroenterol. 2010, 105, 2420-2428. [CrossRef] [PubMed]

7. Rajilic-Stojanovic, M.; Shanahan, F.; Guarner, F.; de Vos, W.M. Phylogenetic analysis of dysbiosis in ulcerative colitis during remission. Inflamm. Bowel. Dis. 2013, 19, 481-488. [CrossRef] [PubMed]

8. Zhang, X.; Shen, D.; Fang, Z.; Jie, Z.; Qiu, X.; Zhang, C.; Chen, Y.; Ji, L. Human gut microbiota changes reveal the progression of glucose intolerance. PLoS ONE 2013, 8, e71108. [CrossRef] [PubMed]

9. Schneeberger, M.; Everard, A.; Gomez-Valades, A.G.; Matamoros, S.; Ramirez, S.; Delzenne, N.M.; Gomis, R.; Claret, M.; Cani, P.D. Akkermansia muciniphila inversely correlates with the onset of inflammation, altered adipose tissue metabolism and metabolic disorders during obesity in mice. Sci. Rep. 2015, 5, 16643. [CrossRef] [PubMed]

10. Everard, A.; Belzer, C.; Geurts, L.; Ouwerkerk, J.P.; Druart, C.; Bindels, L.B.; Guiot, Y.; Derrien, M.; Muccioli, G.G.; Delzenne, N.M.; et al. Cross-talk between Akkermansia muciniphila and intestinal epithelium controls diet-induced obesity. Proc. Natl. Acad. Sci. USA 2013, 110, 9066-9071. [CrossRef] [PubMed]

11. Derrien, M.; Vaughan, E.E.; Plugge, C.M.; de Vos, W.M. Akkermansia muciniphila gen. nov., sp. nov., a human intestinal mucin-degrading bacterium. Int. J. Syst. Evolut. Microbiol. 2004, 54, 1469-1476. [CrossRef] [PubMed]

12. Van Passel, M.W.; Kant, R.; Zoetendal, E.G.; Plugge, C.M.; Derrien, M.; Malfatti, S.A.; Chain, P.S.; Woyke, T.; Palva, A.; de Vos, W.M.; et al. The genome of Akkermansia muciniphila, a dedicated intestinal mucin degrader, and its use in exploring intestinal metagenomes. PLoS ONE 2011, 6, e16876. [CrossRef] [PubMed]

13. De Vos, W.M. Microbe Profile: Akkermansia muciniphila: A conserved intestinal symbiont that acts as the gatekeeper of our mucosa. Microbiology 2017, 163, 646-648. [CrossRef] [PubMed]

14. Swidsinski, A.; Dorffel, Y.; Loening-Baucke, V.; Theissig, F.; Ruckert, J.C.; Ismail, M.; Rau, W.A.; Gaschler, D.; Weizenegger, M.; Kuhn, S.; et al. Acute appendicitis is characterised by local invasion with Fusobacterium nucleatum/necrophorum. Gut 2011, 60,34-40. [CrossRef] [PubMed]

15. Karlsson, C.L.; Onnerfalt, J.; Xu, J.; Molin, G.; Ahrne, S.; Thorngren-Jerneck, K. The microbiota of the gut in preschool children with normal and excessive body weight. Obesity 2012, 20, 2257-2261. [CrossRef] [PubMed]

16. Dao, M.C.; Everard, A.; Aron-Wisnewsky, J.; Sokolovska, N.; Prifti, E.; Verger, E.O.; Kayser, B.D.; Levenez, F.; Chilloux, J.; Hoyles, L.; et al. Akkermansia muciniphila and improved metabolic health during a dietary intervention in obesity: Relationship with gut microbiome richness and ecology. Gut 2015, 65, 426-436. [CrossRef] [PubMed]

17. Korpela, K.; Salonen, A.; Virta, L.J.; Kekkonen, R.A.; Forslund, K.; Bork, P.; de Vos, W.M. Intestinal microbiome is related to lifetime antibiotic use in Finnish pre-school children. Nat. Commun. 2016, 7, 10410. [CrossRef] [PubMed] 
18. Clarke, S.F.; Murphy, E.F.; O'Sullivan, O.; Lucey, A.J.; Humphreys, M.; Hogan, A.; Hayes, P.; O’Reilly, M.; Jeffery, I.B.; Wood-Martin, R.; et al. Exercise and associated dietary extremes impact on gut microbial diversity. Gut 2014, 63, 1913-1920. [CrossRef] [PubMed]

19. Barton, W.; Penney, N.C.; Cronin, O.; Garcia-Perez, I.; Molloy, M.G.; Holmes, E.; Shanahan, F.; Cotter, P.D.; O'Sullivan, O. The microbiome of professional athletes differs from that of more sedentary subjects in composition and particularly at the functional metabolic level. Gut 2018, 67, 625-633. [CrossRef] [PubMed]

20. Derrien, M.; Van Baarlen, P.; Hooiveld, G.; Norin, E.; Muller, M.; de Vos, W.M. Modulation of Mucosal Immune Response, Tolerance, and Proliferation in Mice Colonized by the Mucin-Degrader Akkermansia muciniphila. Front. Microbiol. 2011, 2, 166. [CrossRef] [PubMed]

21. Lukovac, S.; Belzer, C.; Pellis, L.; Keijser, B.J.; de Vos, W.M.; Montijn, R.C.; Roeselers, G. Differential modulation by Akkermansia muciniphila and Faecalibacterium prausnitzii of host peripheral lipid metabolism and histone acetylation in mouse gut organoids. mBio 2014, 5, e1438-14. [CrossRef] [PubMed]

22. Desai, M.S.; Seekatz, A.M.; Koropatkin, N.M.; Kamada, N.; Hickey, C.A.; Wolter, M.; Pudlo, N.A.; Kitamoto, S.; Terrapon, N.; Muller, A.; et al. A Dietary Fiber-Deprived Gut Microbiota Degrades the Colonic Mucus Barrier and Enhances Pathogen Susceptibility. Cell 2016, 167, 1339-1353. [CrossRef] [PubMed]

23. Makki, K.; Deehan, E.C.; Walter, J.; Backhed, F. The Impact of Dietary Fiber on Gut Microbiota in Host Health and Disease. Cell Host Microbe 2018, 23, 705-715. [CrossRef] [PubMed]

24. Reunanen, J.; Kainulainen, V.; Huuskonen, L.; Ottman, N.; Belzer, C.; Huhtinen, H.; de Vos, W.M.; Satokari, R. Akkermansia muciniphila Adheres to Enterocytes and Strengthens the Integrity of the Epithelial Cell Layer. Appl. Environ. Microbiol. 2015, 81, 3655-3662. [CrossRef] [PubMed]

25. Ottman, N.; Huuskonen, L.; Reunanen, J.; Boeren, S.; Klievink, J.; Smidt, H.; Belzer, C.; de Vos, W.M. Characterization of Outer Membrane Proteome of Akkermansia muciniphila Reveals Sets of Novel Proteins Exposed to the Human Intestine. Front. Microbiol. 2016, 7, 1157. [CrossRef] [PubMed]

26. Ottman, N.; Reunanen, J.; Meijerink, M.; Pietila, T.E.; Kainulainen, V.; Klievink, J.; Huuskonen, L.; Aalvink, S.; Skurnik, M.; Boeren, S.; et al. Pili-like proteins of Akkermansia muciniphila modulate host immune responses and gut barrier function. PLoS ONE 2017, 12, e0173004. [CrossRef] [PubMed]

27. Collado, M.C.; Derrien, M.; Isolauri, E.; de Vos, W.M.; Salminen, S. Intestinal integrity and Akkermansia muciniphila, a mucin-degrading member of the intestinal microbiota present in infants, adults, and the elderly. Appl. Environ. Microbiol. 2007, 73, 7767-7770. [CrossRef] [PubMed]

28. Derrien, M.; Collado, M.C.; Ben-Amor, K.; Salminen, S.; de Vos, W.M. The Mucin degrader Akkermansia muciniphila is an abundant resident of the human intestinal tract. Appl. Environ. Microbiol. 2008, 74, 1646-1648. [CrossRef] [PubMed]

29. Grzeskowiak, L.; Gronlund, M.M.; Beckmann, C.; Salminen, S.; von Berg, A.; Isolauri, E. The impact of perinatal probiotic intervention on gut microbiota: Double-blind placebo-controlled trials in Finland and Germany. Anaerobe 2012, 18, 7-13. [CrossRef] [PubMed]

30. Grzeskowiak, L.; Collado, M.C.; Mangani, C.; Maleta, K.; Laitinen, K.; Ashorn, P.; Isolauri, E.; Salminen, S. Distinct gut microbiota in southeastern African and northern European infants. J. Pediatr. Gastroenterol. Nutr. 2012, 54, 812-816. [CrossRef] [PubMed]

31. De Weerth, C.; Fuentes, S.; Puylaert, P.; de Vos, W.M. Intestinal microbiota of infants with colic: Development and specific signatures. Pediatrics 2013. Available online: http:/ / pediatrics.aappublications.org/content/ early/2013/01/08/peds.2012-1449.short (accessed on 18 May 2018).

32. Biagi, E.; Nylund, L.; Candela, M.; Ostan, R.; Bucci, L.; Pini, E.; Nikkila, J.; Monti, D.; Satokari, R.; Franceschi, C.; et al. Through ageing, and beyond: Gut microbiota and inflammatory status in seniors and centenarians. PLoS ONE 2010, 5, e10667. [CrossRef]

33. Biagi, E.; Franceschi, C.; Rampelli, S.; Severgnini, M.; Ostan, R.; Turroni, S.; Consolandi, C.; Quercia, S.; Scurti, M.; Monti, D.; et al. Gut Microbiota and Extreme Longevity. Curr. Biol. 2016, 26, 1480-1485. [CrossRef] [PubMed]

34. Momozawa, Y.; Deffontaine, V.; Louis, E.; Medrano, J.F. Characterization of bacteria in biopsies of colon and stools by high throughput sequencing of the V2 region of bacterial 16S rRNA gene in human. PLoS ONE 2011, 6, e16952. [CrossRef] [PubMed]

35. Li, J.; Jia, H.; Cai, X.; Zhong, H.; Feng, Q.; Sunagawa, S.; Arumugam, M.; Kultima, J.R.; Prifti, E.; Nielsen, T.; et al. An integrated catalog of reference genes in the human gut microbiome. Nat. Biotechnol. 2014, 32, 834-841. [CrossRef] [PubMed] 
36. Smits, S.A.; Leach, J.; Sonnenburg, E.D.; Gonzalez, C.G.; Lichtman, J.S.; Reid, G.; Knight, R.; Manjurano, A.; Changalucha, J.; Elias, J.E.; et al. Seasonal cycling in the gut microbiome of the Hadza hunter-gatherers of Tanzania. Science 2017, 357, 802-806. [CrossRef] [PubMed]

37. Costea, P.I.; Zeller, G.; Sunagawa, S.; Pelletier, E.; Alberti, A.; Levenez, F.; Tramontano, M.; Driessen, M.; Hercog, R.; Jung, F.E.; et al. Towards standards for human fecal sample processing in metagenomic studies. Nat. Biotechnol. 2017, 35, 1069-1076. [CrossRef] [PubMed]

38. Guo, X.; Zhang, J.; Wu, F.; Zhang, M.; Yi, M.; Peng, Y. Different subtype strains of Akkermansia muciniphila abundantly colonize in southern China. J. Appl. Microbiol. 2016, 120, 452-459. [CrossRef] [PubMed]

39. Guo, X.; Li, S.; Zhang, J.; Wu, F.; Li, X.; Wu, D.; Zhang, M.; Ou, Z.; Jie, Z.; Yan, Q.; et al. Genome sequencing of 39 Akkermansia muciniphila isolates reveals its population structure, genomic and functional diverisity, and global distribution in mammalian gut microbiotas. BMC Genom. 2017, 18, 800. [CrossRef] [PubMed]

40. Ouwerkerk, J.P.; Aalvink, S.; Belzer, C.; de Vos, W.M. Akkermansia glycaniphila sp. nov., an anaerobic mucin-degrading bacterium isolated from reticulated python faeces. Int. J. Syst. Evolut. Microbiol. 2016, 66, 4614-4620. [CrossRef] [PubMed]

41. Ouwerkerk, J.P.; Koehorst, J.J.; Schaap, P.J.; Ritari, J.; Paulin, L.; Belzer, C.; de Vos, W.M. Complete Genome Sequence of Akkermansia glycaniphila Strain PytT, a Mucin-Degrading Specialist of the Reticulated Python Gut. Genome Announc. 2017, 5, e01098-16. [CrossRef] [PubMed]

42. Ludwig, W.; Strunk, O.; Westram, R.; Richter, L.; Meier, H.; Yadhukumar, Y.; Buchner, A.; Lai, T.; Steppi, S.; Jobb, G.; et al. ARB: A software environment for sequence data. Nucleic Acids Res. 2004, 32, 1363-1371.

43. Ottman, N.; Davids, M.; Suarez-Diez, M.; Boeren, S.; Schaap, P.J.; Martins Dos Santos, V.A.P.; Smidt, H.; Belzer, C.; de Vos, W.M. Genome-Scale Model and Omics Analysis of Metabolic Capacities of Akkermansia muciniphila Reveal a Preferential Mucin-Degrading Lifestyle. Appl. Environ. Microbiol. 2017, 83, e01014-17. [CrossRef] [PubMed]

44. Ouwerkerk, J.P.; van der Ark, K.C.; Davids, M.; Claassens, N.J.; Robert Finestra, T.; de Vos, W.M.; Belzer, C. Adaptation of Akkermansia muciniphila to the oxic-anoxic interface of the mucus layer. Appl. Environ. Microbiol. 2016, 82, 6983-6993. [CrossRef] [PubMed]

45. Van der Ark, K.C.H.; Aalvink, S.; Suarez-Diez, M.; Schaap, P.J.; de Vos, W.M.; Belzer, C. Model-driven design of a minimal medium for Akkermansia muciniphila confirms mucus adaptation. Microb. Biotechnol. 2018, 11, 476-485. [CrossRef] [PubMed]

46. Van der Ark, K.C.H.; Nugroho, A.D.W.; Berton-Carabin, C.; Wang, C.; Belzer, C.; de Vos, W.M.; Schroen, K. Encapsulation of the therapeutic microbe Akkermansia muciniphila in a double emulsion enhances survival in simulated gastric conditions. Food Res. Int. 2017, 102, 372-379. [CrossRef] [PubMed]

47. Pierre, J.F.; Martinez, K.B.; Ye, H.; Nadimpalli, A.; Morton, T.C.; Yang, J.; Wang, Q.; Patno, N.; Chang, E.B.; Yin, D.P. Activation of bile acid signaling improves metabolic phenotypes in high-fat diet-induced obese mice. Am. J. Physiol. Gastrointest. Liver Physiol. 2016, 311, G286-G304. [CrossRef] [PubMed]

48. Van der Ark, K. Metabolic Characterization and Viable Delivery of Akkermansia muciniphila for Its Future Application. Ph.D. Thesis, Wageningen University, Wageningen, The Netherlands, 2018.

49. Dubourg, G.; Lagier, J.C.; Armougom, F.; Robert, C.; Audoly, G.; Papazian, L.; Raoult, D. High-level colonisation of the human gut by Verrucomicrobia following broad-spectrum antibiotic treatment. Int. J. Antimicrob. Agents 2013, 41, 149-155. [CrossRef] [PubMed]

50. Dubourg, G.; Cornu, F.; Edouard, S.; Battaini, A.; Tsimaratos, M.; Raoult, D. First isolation of Akkermansia muciniphila in a blood-culture sample. Clin. Microbiol. Infect. 2017, 23, 682-683. [CrossRef] [PubMed]

51. Caputo, A.; Dubourg, G.; Croce, O.; Gupta, S.; Robert, C.; Papazian, L.; Rolain, J.M.; Raoult, D. Whole-genome assembly of Akkermansia muciniphila sequenced directly from human stool. Biol. Direct 2015, 10, 5. [CrossRef] [PubMed]

52. Espey, M.G. Role of oxygen gradients in shaping redox relationships between the human intestine and its microbiota. Free Radic. Biol. Med. 2013, 55, 130-140. [CrossRef] [PubMed]

53. Johansson, M.E.; Ambort, D.; Pelaseyed, T.; Schutte, A.; Gustafsson, J.K.; Ermund, A.; Subramani, D.B.; Holmen-Larsson, J.M.; Thomsson, K.A.; Bergstrom, J.H.; et al. Composition and functional role of the mucus layers in the intestine. Cell. Mol. Life Sci. 2011, 68, 3635-3641. [CrossRef] [PubMed] 
54. Santiago, A.; Pozuelo, M.; Poca, M.; Gely, C.; Nieto, J.C.; Torras, X.; Roman, E.; Campos, D.; Sarrabayrouse, G.; Vidal, S.; et al. Alteration of the serum microbiome composition in cirrhotic patients with ascites. Sci. Rep. 2016, 6, 25001. [CrossRef] [PubMed]

55. Traykova, D.; Schneider, B.; Chojkier, M.; Buck, M. Blood Microbiome Quantity and the Hyperdynamic Circulation in Decompensated Cirrhotic Patients. PLoS ONE 2017, 12, e0169310. [CrossRef] [PubMed]

56. Gomez-Gallego, C.; Collado, M.C.; Perez, G.; Ilo, T.; Jaakkola, U.M.; Bernal, M.J.; Periago, M.J.; Frias, R.; Ros, G.; Salminen, S. Resembling breast milk: Influence of polyamine-supplemented formula on neonatal BALB/cOlaHsd mouse microbiota. Br. J. Nutr. 2014, 111, 1050-1058. [CrossRef] [PubMed]

57. Marcotte, H.; Lavoie, M.C. Oral microbial ecology and the role of salivary immunoglobulin A. Microbiol. Mol. Biol. Rev. 1998, 62, 71-109. [PubMed]

58. Aframian, D.J.; Davidowitz, T.; Benoliel, R. The distribution of oral mucosal $\mathrm{pH}$ values in healthy saliva secretors. Oral Dis. 2006, 12, 420-423. [CrossRef] [PubMed]

59. Aas, J.A.; Paster, B.J.; Stokes, L.N.; Olsen, I.; Dewhirst, F.E. Defining the normal bacterial flora of the oral cavity. J. Clin. Microbiol. 2005, 43, 5721-5732. [CrossRef] [PubMed]

60. Shaw, L.; Ribeiro, A.L.R.; Levine, A.P.; Pontikos, N.; Balloux, F.; Segal, A.W.; Roberts, A.P.; Smith, A.M. The Human Salivary Microbiome Is Shaped by Shared Environment Rather than Genetics: Evidence from a Large Family of Closely Related Individuals. mBio 2017, 8, e01237-17. [CrossRef] [PubMed]

61. Bik, E.M.; Long, C.D.; Armitage, G.C.; Loomer, P.; Emerson, J.; Mongodin, E.F.; Nelson, K.E.; Gill, S.R.; Fraser-Liggett, C.M.; Relman, D.A. Bacterial diversity in the oral cavity of 10 healthy individuals. ISME J. 2010, 4, 962-974. [CrossRef] [PubMed]

62. Nasidze, I.; Quinque, D.; Li, J.; Li, M.; Tang, K.; Stoneking, M. Comparative analysis of human saliva microbiome diversity by barcoded pyrosequencing and cloning approaches. Anal. Biochem. 2009, 391, 64-68. [CrossRef] [PubMed]

63. Sarkar, A.; Stoneking, M.; Nandineni, M.R. Unraveling the human salivary microbiome diversity in Indian populations. PLoS ONE 2017, 12, e0184515. [CrossRef] [PubMed]

64. Leake, S.L.; Pagni, M.; Falquet, L.; Taroni, F.; Greub, G. The salivary microbiome for differentiating individuals: Proof of principle. Microbes Infect. 2016, 18, 399-405. [CrossRef] [PubMed]

65. Ye, F.; Shen, H.; Li, Z.; Meng, F.; Li, L.; Yang, J.; Chen, Y.; Bo, X.; Zhang, X.; Ni, M. Influence of the Biliary System on Biliary Bacteria Revealed by Bacterial Communities of the Human Biliary and Upper Digestive Tracts. PLoS ONE 2016, 11, e0150519. [CrossRef] [PubMed]

66. Marsh, P.D.; Head, D.A.; Devine, D.A. Ecological approaches to oral biofilms: Control without killing. Caries Res. 2015, 49 (Suppl. 1), 46-54. [CrossRef] [PubMed]

67. Linden, S.K.; Sutton, P.; Karlsson, N.G.; Korolik, V.; McGuckin, M.A. Mucins in the mucosal barrier to infection. Mucosal Immunol. 2008, 1, 183-197. [CrossRef] [PubMed]

68. Nielsen, P.A.; Bennett, E.P.; Wandall, H.H.; Therkildsen, M.H.; Hannibal, J.; Clausen, H. Identification of a major human high molecular weight salivary mucin (MG1) as tracheobronchial mucin MUC5B. Glycobiology 1997, 7, 413-419. [CrossRef] [PubMed]

69. Thornton, D.J.; Khan, N.; Mehrotra, R.; Howard, M.; Veerman, E.; Packer, N.H.; Sheehan, J.K. Salivary mucin MG1 is comprised almost entirely of different glycosylated forms of the MUC5B gene product. Glycobiology 1999, 9, 293-302. [CrossRef] [PubMed]

70. Van der Hoeven, J.S.; van den Kieboom, C.W.; Camp, P.J. Utilization of mucin by oral Streptococcus species. Antonie Leeuwenhoek 1990, 57, 165-172. [CrossRef] [PubMed]

71. Derrien, M.; van Passel, M.W.; van de Bovenkamp, J.H.; Schipper, R.G.; de Vos, W.M.; Dekker, J. Mucin-bacterial interactions in the human oral cavity and digestive tract. Gut Microbes 2010, 1, 254-268. [CrossRef] [PubMed]

72. Tan, G.D. The pancreas. Anaesth. Intensive Care Med. 2014, 15, 485-488. [CrossRef]

73. Leal-Lopes, C.; Velloso, F.J.; Campopiano, J.C.; Sogayar, M.C.; Correa, R.G. Roles of Commensal Microbiota in Pancreas Homeostasis and Pancreatic Pathologies. J. Diabetes Res. 2015, 2015, 284680. [CrossRef] [PubMed]

74. Jouvet, N.; Estall, J.L. The pancreas: Bandmaster of glucose homeostasis. Exp. Cell Res. 2017, 360, 19-23. [CrossRef] [PubMed]

75. Patel, A.G.; Toyama, M.T.; Alvarez, C.; Nguyen, T.N.; Reber, P.U.; Ashley, S.W.; Reber, H.A. Pancreatic interstitial $\mathrm{pH}$ in human and feline chronic pancreatitis. Gastroenterology 1995, 109, 1639-1645. [CrossRef] 
76. Memba, R.; Duggan, S.N.; Ni Chonchubhair, H.M.; Griffin, O.M.; Bashir, Y.; O'Connor, D.B.; Murphy, A.; McMahon, J.; Volcov, Y.; Ryan, B.M.; et al. The potential role of gut microbiota in pancreatic disease: A systematic review. Pancreatology 2017, 17, 867-874. [CrossRef] [PubMed]

77. Rogers, M.B.; Aveson, V.; Firek, B.; Yeh, A.; Brooks, B.; Brower-Sinning, R.; Steve, J.; Banfield, J.F.; Zureikat, A.; Hogg, M.; et al. Disturbances of the Perioperative Microbiome Across Multiple Body Sites in Patients Undergoing Pancreaticoduodenectomy. Pancreas 2017, 46, 260-267. [CrossRef] [PubMed]

78. Nishiyama, H.; Nagai, T.; Kudo, M.; Okazaki, Y.; Azuma, Y.; Watanabe, T.; Goto, S.; Ogata, H.; Sakurai, T. Supplementation of pancreatic digestive enzymes alters the composition of intestinal microbiota in mice. Biochem. Biophys. Res. Commun. 2018, 495, 273-279. [CrossRef] [PubMed]

79. Boyer, J.L. Mechanisms of bile secretion and hepatic transport. In Physiology of Membrane Disorders; Andreoli, T.E., Hoffman, J.F., Fanestil, D.D., Schultz, S.G., Eds.; Springer: Boston, MA, USA, 1986; pp. $609-636$.

80. Sutor, D.J.; Wilkie, L.I. Diurnal variations in the $\mathrm{pH}$ of pathological gallbladder bile. Gut 1976, 17, 971-974. [CrossRef] [PubMed]

81. Boyer, J.L. Bile formation and secretion. Compr. Physiol. 2013, 3, 1035-1078. [PubMed]

82. Islam, K.B.; Fukiya, S.; Hagio, M.; Fujii, N.; Ishizuka, S.; Ooka, T.; Ogura, Y.; Hayashi, T.; Yokota, A. Bile acid is a host factor that regulates the composition of the cecal microbiota in rats. Gastroenterology 2011, 141, 1773-1781. [CrossRef] [PubMed]

83. Inagaki, T.; Moschetta, A.; Lee, Y.K.; Peng, L.; Zhao, G.; Downes, M.; Yu, R.T.; Shelton, J.M.; Richardson, J.A.; Repa, J.J.; et al. Regulation of antibacterial defense in the small intestine by the nuclear bile acid receptor. Proc. Natl. Acad. Sci. USA 2006, 103, 3920-3925. [CrossRef] [PubMed]

84. Gass, J.; Vora, H.; Hofmann, A.F.; Gray, G.M.; Khosla, C. Enhancement of dietary protein digestion by conjugated bile acids. Gastroenterology 2007, 133, 16-23. [CrossRef] [PubMed]

85. Hofmann, A.F. The enterohepatic circulation of bile acids in man. Adv. Intern. Med. 1976, 21, 501-534. [PubMed]

86. Csendes, A.; Fernandez, M.; Uribe, P. Bacteriology of the gallbladder bile in normal subjects. Am. J. Surg. 1975, 129, 629-631. [CrossRef]

87. Shen, H.; Ye, F.; Xie, L.; Yang, J.; Li, Z.; Xu, P.; Meng, F.; Li, L.; Chen, Y.; Bo, X.; et al. Metagenomic sequencing of bile from gallstone patients to identify different microbial community patterns and novel biliary bacteria. Sci. Rep. 2015, 5, 17450. [CrossRef] [PubMed]

88. Wu, T.; Zhang, Z.; Liu, B.; Hou, D.; Liang, Y.; Zhang, J.; Shi, P. Gut microbiota dysbiosis and bacterial community assembly associated with cholesterol gallstones in large-scale study. BMC Genom. 2013, 14, 669. [CrossRef] [PubMed]

89. Pereira, P.; Aho, V.; Arola, J.; Boyd, S.; Jokelainen, K.; Paulin, L.; Auvinen, P.; Farkkila, M. Bile microbiota in primary sclerosing cholangitis: Impact on disease progression and development of biliary dysplasia. PLoS ONE 2017, 12, e0182924. [CrossRef] [PubMed]

90. Scheithauer, B.K.; Wos-Oxley, M.L.; Ferslev, B.; Jablonowski, H.; Pieper, D.H. Characterization of the complex bacterial communities colonizing biliary stents reveals a host-dependent diversity. ISME J. 2009, 3, 797-807. [CrossRef] [PubMed]

91. Stearns, J.C.; Lynch, M.D.; Senadheera, D.B.; Tenenbaum, H.C.; Goldberg, M.B.; Cvitkovitch, D.G.; Croitoru, K.; Moreno-Hagelsieb, G.; Neufeld, J.D. Bacterial biogeography of the human digestive tract. Sci. Rep. 2011, 1, 170. [CrossRef] [PubMed]

92. Belzer, C.; Kusters, J.G.; Kuipers, E.J.; van Vliet, A.H. Urease induced calcium precipitation by Helicobacter species may initiate gallstone formation. Gut 2006, 55, 1678-1679. [CrossRef] [PubMed]

93. Saltykova, I.V.; Petrov, V.A.; Logacheva, M.D.; Ivanova, P.G.; Merzlikin, N.V.; Sazonov, A.E.; Ogorodova, L.M.; Brindley, P.J. Biliary Microbiota, Gallstone Disease and Infection with Opisthorchis felineus. PLoS Negl. Trop. Dis. 2016, 10, e0004809. [CrossRef] [PubMed]

94. Fedorova, O.S.; Fedotova, M.M.; Sokolova, T.S.; Golovach, E.A.; Kovshirina, Y.V.; Ageeva, T.S.; Kovshirina, A.E.; Kobyakova, O.S.; Ogorodova, L.M.; Odermatt, P. Opisthorchis felineus infection prevalence in Western Siberia: A review of Russian literature. Acta Trop. 2018, 178, 196-204. [CrossRef] [PubMed]

95. Fanning, S.; Hall, L.J.; Cronin, M.; Zomer, A.; MacSharry, J.; Goulding, D.; Motherway, M.O.; Shanahan, F.; Nally, K.; Dougan, G.; et al. Bifidobacterial surface-exopolysaccharide facilitates commensal-host interaction through immune modulation and pathogen protection. Proc. Natl. Acad. Sci. USA 2012, 109, 2108-2113. [CrossRef] [PubMed] 
96. Ruas-Madiedo, P.; Gueimonde, M.; Arigoni, F.; de los Reyes-Gavilan, C.G.; Margolles, A. Bile affects the synthesis of exopolysaccharides by Bifidobacterium animalis. Appl. Environ. Microbiol. 2009, 75, 1204-1207. [CrossRef] [PubMed]

97. Gum, J.R., Jr.; Ho, J.J.; Pratt, W.S.; Hicks, J.W.; Hill, A.S.; Vinall, L.E.; Roberton, A.M.; Swallow, D.M.; Kim, Y.S. MUC3 human intestinal mucin. Analysis of gene structure, the carboxyl terminus, and a novel upstream repetitive region. J. Biol. Chem. 1997, 272, 26678-26686. [CrossRef] [PubMed]

98. Pigny, P.; Guyonnet-Duperat, V.; Hill, A.S.; Pratt, W.S.; Galiegue-Zouitina, S.; d'Hooge, M.C.; Laine, A.; Van-Seuningen, I.; Degand, P.; Gum, J.R.; et al. Human mucin genes assigned to 11p15.5: Identification and organization of a cluster of genes. Genomics 1996, 38, 340-352. [CrossRef] [PubMed]

99. Keates, A.C.; Nunes, D.P.; Afdhal, N.H.; Troxler, R.F.; Offner, G.D. Molecular cloning of a major human gall bladder mucin: Complete C-terminal sequence and genomic organization of MUC5B. Biochem. J. 1997, 324, 295-303. [CrossRef] [PubMed]

100. Yoo, K.S.; Choi, H.S.; Jun, D.W.; Lee, H.L.; Lee, O.Y.; Yoon, B.C.; Lee, K.G.; Paik, S.S.; Kim, Y.S.; Lee, J. MUC Expression in Gallbladder Epithelial Tissues in Cholesterol-Associated Gallbladder Disease. Gut Liver 2016, 10, 851-858. [CrossRef] [PubMed]

101. Zoetendal, E.G.; Raes, J.; van den Bogert, B.; Arumugam, M.; Booijink, C.C.; Troost, F.J.; Bork, P.; Wels, M.; de Vos, W.M.; Kleerebezem, M. The human small intestinal microbiota is driven by rapid uptake and conversion of simple carbohydrates. ISME J. 2012, 6, 1415-1426. [CrossRef] [PubMed]

102. Savage, D.C. Microbial ecology of the gastrointestinal tract. Annu. Rev. Microbiol. 1977, 31, 107-133. [CrossRef] [PubMed]

103. Hung, G.U.; Tsai, C.C.; Lin, W.Y. Development of a new method for small bowel transit study. Ann. Nucl. Med. 2006, 20, 387-392. [CrossRef] [PubMed]

104. Ovesen, L.; Bendtsen, F.; Tage-Jensen, U.; Pedersen, N.T.; Gram, B.R.; Rune, S.J. Intraluminal pH in the stomach, duodenum, and proximal jejunum in normal subjects and patients with exocrine pancreatic insufficiency. Gastroenterology 1986, 90, 958-962. [CrossRef]

105. Koziolek, M.; Grimm, M.; Becker, D.; Iordanov, V.; Zou, H.; Shimizu, J.; Wanke, C.; Garbacz, G.; Weitschies, W. Investigation of $\mathrm{pH}$ and Temperature Profiles in the GI Tract of Fasted Human Subjects Using the Intellicap((R)) System. J. Pharm. Sci. 2015, 104, 2855-2863. [CrossRef] [PubMed]

106. Atuma, C.; Strugala, V.; Allen, A.; Holm, L. The adherent gastrointestinal mucus gel layer: Thickness and physical state in vivo. Am. J. Physiol. Gastrointest. Liver Physiol. 2001, 280, G922-G929. [CrossRef] [PubMed]

107. Johansson, M.E.; Phillipson, M.; Petersson, J.; Velcich, A.; Holm, L.; Hansson, G.C. The inner of the two Muc2 mucin-dependent mucus layers in colon is devoid of bacteria. Proc. Natl. Acad. Sci. USA 2008, 105, 15064-15069. [CrossRef] [PubMed]

108. Sender, R.; Fuchs, S.; Milo, R. Revised Estimates for the Number of Human and Bacteria Cells in the Body. PLoS Biol. 2016, 14, e1002533. [CrossRef] [PubMed]

109. Donaldson, G.P.; Lee, S.M.; Mazmanian, S.K. Gut biogeography of the bacterial microbiota. Nat. Rev. Microbiol. 2016, 14, 20-32. [CrossRef] [PubMed]

110. Morikawa, M.; Tsujibe, S.; Kiyoshima-Shibata, J.; Watanabe, Y.; Kato-Nagaoka, N.; Shida, K.; Matsumoto, S. Microbiota of the Small Intestine Is Selectively Engulfed by Phagocytes of the Lamina Propria and Peyer's Patches. PLoS ONE 2016, 11, e0163607. [CrossRef] [PubMed]

111. Sundin, O.H.; Mendoza-Ladd, A.; Zeng, M.; Diaz-Arevalo, D.; Morales, E.; Fagan, B.M.; Ordonez, J.; Velez, P.; Antony, N.; McCallum, R.W. The human jejunum has an endogenous microbiota that differs from those in the oral cavity and colon. BMC Microbiol. 2017, 17, 160. [CrossRef] [PubMed]

112. Angelakis, E.; Armougom, F.; Carriere, F.; Bachar, D.; Laugier, R.; Lagier, J.C.; Robert, C.; Michelle, C.; Henrissat, B.; Raoult, D. A Metagenomic Investigation of the Duodenal Microbiota Reveals Links with Obesity. PLoS ONE 2015, 10, e0137784. [CrossRef] [PubMed]

113. Shanahan, E.R.; Zhong, L.; Talley, N.J.; Morrison, M.; Holtmann, G. Characterisation of the gastrointestinal mucosa-associated microbiota: A novel technique to prevent cross-contamination during endoscopic procedures. Aliment. Pharmacol. Ther. 2016, 43, 1186-1196. [CrossRef] [PubMed]

114. Li, E.; Hamm, C.M.; Gulati, A.S.; Sartor, R.B.; Chen, H.; Wu, X.; Zhang, T.; Rohlf, F.J.; Zhu, W.; Gu, C.; et al. Inflammatory bowel diseases phenotype, C. difficile and NOD2 genotype are associated with shifts in human ileum associated microbial composition. PLoS ONE 2012, 7, e26284. [CrossRef] [PubMed] 
115. Hartman, A.L.; Lough, D.M.; Barupal, D.K.; Fiehn, O.; Fishbein, T.; Zasloff, M.; Eisen, J.A. Human gut microbiome adopts an alternative state following small bowel transplantation. Proc. Natl. Acad. Sci. USA 2009, 106, 17187-17192. [CrossRef] [PubMed]

116. Haberman, Y.; Tickle, T.L.; Dexheimer, P.J.; Kim, M.O.; Tang, D.; Karns, R.; Baldassano, R.N.; Noe, J.D.; Rosh, J.; Markowitz, J.; et al. Pediatric Crohn disease patients exhibit specific ileal transcriptome and microbiome signature. J. Clin. Investig. 2014, 124, 3617-3633. [CrossRef] [PubMed]

117. Dlugosz, A.; Winckler, B.; Lundin, E.; Zakikhany, K.; Sandstrom, G.; Ye, W.; Engstrand, L.; Lindberg, G. No difference in small bowel microbiota between patients with irritable bowel syndrome and healthy controls. Sci. Rep. 2015, 5, 8508. [CrossRef] [PubMed]

118. Chen, Y.; Ji, F.; Guo, J.; Shi, D.; Fang, D.; Li, L. Dysbiosis of small intestinal microbiota in liver cirrhosis and its association with etiology. Sci. Rep. 2016, 6, 34055. [CrossRef] [PubMed]

119. Assa, A.; Butcher, J.; Li, J.; Elkadri, A.; Sherman, P.M.; Muise, A.M.; Stintzi, A.; Mack, D. Mucosa-Associated Ileal Microbiota in New-Onset Pediatric Crohn's Disease. Inflamm. Bowel. Dis. 2016, 22, 1533-1539. [CrossRef] [PubMed]

120. Li, G.; Yang, M.; Zhou, K.; Zhang, L.; Tian, L.; Lv, S.; Jin, Y.; Qian, W.; Xiong, H.; Lin, R.; et al. Diversity of Duodenal and Rectal Microbiota in Biopsy Tissues and Luminal Contents in Healthy Volunteers. J. Microbiol. Biotechnol. 2015, 25, 1136-1145. [CrossRef] [PubMed]

121. Wang, M.; Ahrne, S.; Jeppsson, B.; Molin, G. Comparison of bacterial diversity along the human intestinal tract by direct cloning and sequencing of $16 \mathrm{~S}$ rRNA genes. FEMS Microbiol. Ecol. 2005, 54, 219-231. [CrossRef] [PubMed]

122. Rossen, N.G.; Fuentes, S.; Boonstra, K.; D’Haens, G.R.; Heilig, H.G.; Zoetendal, E.G.; de Vos, W.M.; Ponsioen, C.Y. The mucosa-associated microbiota of PSC patients is characterized by low diversity and low abundance of uncultured Clostridiales II. J. Crohns Colitis 2015, 9, 342-348. [CrossRef] [PubMed]

123. Patrascu, O.; Beguet-Crespel, F.; Marinelli, L.; Le Chatelier, E.; Abraham, A.L.; Leclerc, M.; Klopp, C.; Terrapon, N.; Henrissat, B.; Blottiere, H.M.; et al. A fibrolytic potential in the human ileum mucosal microbiota revealed by functional metagenomic. Sci. Rep. 2017, 7, 40248. [CrossRef] [PubMed]

124. Plovier, H.; Everard, A.; Druart, C.; Depommier, C.; Van Hul, M.; Geurts, L.; Chilloux, J.; Ottman, N.; Duparc, T.; Lichtenstein, L.; et al. A purified membrane protein from Akkermansia muciniphila or the pasteurized bacterium improves metabolism in obese and diabetic mice. Nat. Med. 2017, 23, 107-113. [CrossRef] [PubMed]

125. Macfarlane, G.T.; Macfarlane, S. Models for intestinal fermentation: Association between food components, delivery systems, bioavailability and functional interactions in the gut. Curr. Opin. Biotechnol. 2007, 18, 156-162. [CrossRef] [PubMed]

126. Madsen, J.L. Effects of gender, age, and body mass index on gastrointestinal transit times. Dig. Dis. Sci. 1992, 37, 1548-1553. [CrossRef] [PubMed]

127. Nugent, S.G.; Kumar, D.; Rampton, D.S.; Evans, D.F. Intestinal luminal pH in inflammatory bowel disease: Possible determinants and implications for therapy with aminosalicylates and other drugs. Gut 2001, 48, 571-577. [CrossRef] [PubMed]

128. McDougall, C.J.; Wong, R.; Scudera, P.; Lesser, M.; DeCosse, J.J. Colonic mucosal pH in humans. Dig. Dis. Sci. 1993, 38, 542-545. [CrossRef] [PubMed]

129. Johansson, M.E.; Larsson, J.M.; Hansson, G.C. The two mucus layers of colon are organized by the MUC2 mucin, whereas the outer layer is a legislator of host-microbial interactions. Proc. Natl. Acad. Sci. USA 2011, 108 (Suppl. 1), 4659-4665. [CrossRef] [PubMed]

130. Ambort, D.; Johansson, M.E.; Gustafsson, J.K.; Nilsson, H.E.; Ermund, A.; Johansson, B.R.; Koeck, P.J.; Hebert, H.; Hansson, G.C. Calcium and pH-dependent packing and release of the gel-forming MUC2 mucin. Proc. Natl. Acad. Sci. USA 2012, 109, 5645-5650. [CrossRef] [PubMed]

131. Johansson, M.E.; Hansson, G.C. Immunological aspects of intestinal mucus and mucins. Nat. Rev. Immunol. 2016, 16, 639-649. [CrossRef] [PubMed]

132. Zhang, Z.; Geng, J.; Tang, X.; Fan, H.; Xu, J.; Wen, X.; Ma, Z.S.; Shi, P. Spatial heterogeneity and co-occurrence patterns of human mucosal-associated intestinal microbiota. ISME J. 2014, 8, 881-893. [CrossRef] [PubMed]

133. Arumugam, M.; Raes, J.; Pelletier, E.; Le Paslier, D.; Yamada, T.; Mende, D.R.; Fernandes, G.R.; Tap, J.; Bruls, T.; Batto, J.M.; et al. Enterotypes of the human gut microbiome. Nature 2011, 473, 174-180. [CrossRef] [PubMed] 
134. Costea, P.I.; Hildebrand, F.; Arumugam, M.; Backhed, F.; Blaser, M.J.; Bushman, F.D.; de Vos, W.M.; Ehrlich, S.D.; Fraser, C.M.; Hattori, M.; et al. Enterotypes in the landscape of gut microbial community composition. Nat. Microbiol. 2018, 3, 8-16. [CrossRef] [PubMed]

135. Walker, A.W.; Sanderson, J.D.; Churcher, C.; Parkes, G.C.; Hudspith, B.N.; Rayment, N.; Brostoff, J.; Parkhill, J.; Dougan, G.; Petrovska, L. High-throughput clone library analysis of the mucosa-associated microbiota reveals dysbiosis and differences between inflamed and non-inflamed regions of the intestine in inflammatory bowel disease. BMC Microbiol. 2011, 11, 7. [CrossRef] [PubMed]

136. Codling, C.; O’Mahony, L.; Shanahan, F.; Quigley, E.M.; Marchesi, J.R. A molecular analysis of fecal and mucosal bacterial communities in irritable bowel syndrome. Dig. Dis. Sci. 2010, 55, 392-397. [CrossRef] [PubMed]

137. Carroll, I.M.; Ringel-Kulka, T.; Siddle, J.P.; Ringel, Y. Alterations in composition and diversity of the intestinal microbiota in patients with diarrhea-predominant irritable bowel syndrome. Neurogastroenterol. Motil. 2012, 24, 521-530. [CrossRef] [PubMed]

138. Tap, J.; Derrien, M.; Tornblom, H.; Brazeilles, R.; Cools-Portier, S.; Dore, J.; Storsrud, S.; Le Neve, B.; Ohman, L.; Simren, M. Identification of an Intestinal Microbiota Signature Associated With Severity of Irritable Bowel Syndrome. Gastroenterology 2017, 152, 111-123. [CrossRef] [PubMed]

139. Ley, R.E.; Backhed, F.; Turnbaugh, P.; Lozupone, C.A.; Knight, R.D.; Gordon, J.I. Obesity alters gut microbial ecology. Proc. Natl. Acad. Sci. USA 2005, 102, 11070-11075. [CrossRef] [PubMed]

140. Schwiertz, A.; Taras, D.; Schafer, K.; Beijer, S.; Bos, N.A.; Donus, C.; Hardt, P.D. Microbiota and SCFA in lean and overweight healthy subjects. Obesity 2010, 18, 190-195. [CrossRef] [PubMed]

141. Qin, J.; Li, Y.; Cai, Z.; Li, S.; Zhu, J.; Zhang, F.; Liang, S.; Zhang, W.; Guan, Y.; Shen, D.; et al. A metagenome-wide association study of gut microbiota in type 2 diabetes. Nature 2012, 490, 55-60. [CrossRef] [PubMed]

142. Cummings, J.H.; Macfarlane, G.T. The control and consequences of bacterial fermentation in the human colon. J. Appl. Bacteriol. 1991, 70, 443-459. [CrossRef] [PubMed]

143. Clausen, M.R.; Mortensen, P.B. Kinetic studies on colonocyte metabolism of short chain fatty acids and glucose in ulcerative colitis. Gut 1995, 37, 684-689. [CrossRef] [PubMed]

144. Le Poul, E.; Loison, C.; Struyf, S.; Springael, J.Y.; Lannoy, V.; Decobecq, M.E.; Brezillon, S.; Dupriez, V.; Vassart, G.; Van Damme, J.; et al. Functional characterization of human receptors for short chain fatty acids and their role in polymorphonuclear cell activation. J. Biol. Chem. 2003, 278, 25481-25489. [CrossRef] [PubMed]

145. Brown, A.J.; Goldsworthy, S.M.; Barnes, A.A.; Eilert, M.M.; Tcheang, L.; Daniels, D.; Muir, A.I.; Wigglesworth, M.J.; Kinghorn, I.; Fraser, N.J.; et al. The Orphan G protein-coupled receptors GPR41 and GPR43 are activated by propionate and other short chain carboxylic acids. J. Biol. Chem. 2003, 278, 11312-11319. [CrossRef] [PubMed]

146. Nilsson, N.E.; Kotarsky, K.; Owman, C.; Olde, B. Identification of a free fatty acid receptor, FFA2R, expressed on leukocytes and activated by short-chain fatty acids. Biochem. Biophys. Res. Commun. 2003, 303, 1047-1052. [CrossRef]

147. Flint, H.J.; Scott, K.P.; Louis, P.; Duncan, S.H. The role of the gut microbiota in nutrition and health. Nat. Rev. Gastroenterol. Hepatol. 2012, 9, 577-589. [CrossRef] [PubMed]

148. Possemiers, S.; Bolca, S.; Verstraete, W.; Heyerick, A. The intestinal microbiome: A separate organ inside the body with the metabolic potential to influence the bioactivity of botanicals. Fitoterapia 2011, 82, 53-66. [CrossRef] [PubMed]

149. Kamada, N.; Chen, G.Y.; Inohara, N.; Nunez, G. Control of pathogens and pathobionts by the gut microbiota. Nat. Immunol. 2013, 14, 685-690. [CrossRef] [PubMed]

150. McHardy, I.H.; Goudarzi, M.; Tong, M.; Ruegger, P.M.; Schwager, E.; Weger, J.R.; Graeber, T.G.; Sonnenburg, J.L.; Horvath, S.; Huttenhower, C.; et al. Integrative analysis of the microbiome and metabolome of the human intestinal mucosal surface reveals exquisite inter-relationships. Microbiome 2013, 1, 17. [CrossRef] [PubMed]

151. Lyra, A.; Forssten, S.; Rolny, P.; Wettergren, Y.; Lahtinen, S.J.; Salli, K.; Cedgard, L.; Odin, E.; Gustavsson, B.; Ouwehand, A.C. Comparison of bacterial quantities in left and right colon biopsies and faeces. World J. Gastroenterol. 2012, 18, 4404-4411. [CrossRef] [PubMed] 
152. Hong, P.Y.; Croix, J.A.; Greenberg, E.; Gaskins, H.R.; Mackie, R.I. Pyrosequencing-based analysis of the mucosal microbiota in healthy individuals reveals ubiquitous bacterial groups and micro-heterogeneity. PLoS ONE 2011, 6, e25042. [CrossRef] [PubMed]

153. Sanapareddy, N.; Legge, R.M.; Jovov, B.; McCoy, A.; Burcal, L.; Araujo-Perez, F.; Randall, T.A.; Galanko, J.; Benson, A.; Sandler, R.S.; et al. Increased rectal microbial richness is associated with the presence of colorectal adenomas in humans. ISME J. 2012, 6, 1858-1868. [CrossRef] [PubMed]

154. Belzer, C.; Chia, L.W.; Aalvink, S.; Chamlagain, B.; Piironen, V.; Knol, J.; de Vos, W.M. Microbial Metabolic Networks at the Mucus Layer Lead to Diet-Independent Butyrate and Vitamin B12 Production by Intestinal Symbionts. mBio 2017, 8, e00770-17. [CrossRef] [PubMed]

155. Derrien, M. Mucin Utilisation and Host Interactions of the Novel Intestinal Microbe Akkermansia muciniphila. Ph.D. Thesis, Wageningen University, Wageningen, The Netherlands, 2007.

156. Willis, C.L.; Cummings, J.H.; Neale, G.; Gibson, G.R. In VitroEffects of Mucin Fermentation on the Growth of Human Colonic Sulphate-Reducing Bacteria: Ecology. Anaerobe 1996, 2, 117-122. [CrossRef]

157. Ottman, N.; Geerlings, S.Y.; Aalvink, S.; de Vos, W.M.; Belzer, C. Action and function of Akkermansia muciniphila in microbiome ecology, health and disease. Best Pract. Res. Clin. Gastroenterol. 2017, 31, 637-642. [CrossRef] [PubMed]

158. Randal Bollinger, R.; Barbas, A.S.; Bush, E.L.; Lin, S.S.; Parker, W. Biofilms in the large bowel suggest an apparent function of the human vermiform appendix. J. Theor. Biol. 2007, 249, 826-831. [CrossRef] [PubMed]

159. Darwin, C. The Descent of Man and Selection in Relation to Sex Darwin; John Murray: London, UK, 1871.

160. Smith, H.F.; Parker, W.; Kotzé, S.H.; Laurin, M. Multiple independent appearances of the cecal appendix in mammalian evolution and an investigation of related ecological and anatomical factors. C. R. Palevol. 2013, 12, 339-354. [CrossRef]

161. Berry, R.J. The True Caecal Apex, or the Vermiform Appendix: Its Minute and Comparative Anatomy. J. Anat. Physiol. 1900, 35, 83-100. [PubMed]

162. Merchant, H.A.; McConnell, E.L.; Liu, F.; Ramaswamy, C.; Kulkarni, R.P.; Basit, A.W.; Murdan, S. Assessment of gastrointestinal $\mathrm{pH}$, fluid and lymphoid tissue in the guinea pig, rabbit and pig, and implications for their use in drug development. Eur. J. Pharm. Sci. 2011, 42, 3-10. [CrossRef] [PubMed]

163. Zhong, D.; Brower-Sinning, R.; Firek, B.; Morowitz, M.J. Acute appendicitis in children is associated with an abundance of bacteria from the phylum Fusobacteria. J. Pediatr. Surg. 2014, 49, 441-446. [CrossRef] [PubMed]

164. Jackson, H.T.; Mongodin, E.F.; Davenport, K.P.; Fraser, C.M.; Sandler, A.D.; Zeichner, S.L. Culture-independent evaluation of the appendix and rectum microbiomes in children with and without appendicitis. PLoS ONE 2014, 9, e95414. [CrossRef] [PubMed]

165. Salo, M.; Marungruang, N.; Roth, B.; Sundberg, T.; Stenstrom, P.; Arnbjornsson, E.; Fak, F.; Ohlsson, B. Evaluation of the microbiome in children's appendicitis. Int. J. Colorectal. Dis. 2017, 32, 19-28. [CrossRef] [PubMed]

166. Guinane, C.M.; Tadrous, A.; Fouhy, F.; Ryan, C.A.; Dempsey, E.M.; Murphy, B.; Andrews, E.; Cotter, P.D.; Stanton, C.; Ross, R.P. Microbial composition of human appendices from patients following appendectomy. mBio 2013, 4, e00366-12. [CrossRef] [PubMed]

167. Bode, L. Human milk oligosaccharides: Every baby needs a sugar mama. Glycobiology 2012, 22, 1147-1162. [CrossRef] [PubMed]

168. Zivkovic, A.M.; German, J.B.; Lebrilla, C.B.; Mills, D.A. Human milk glycobiome and its impact on the infant gastrointestinal microbiota. Proc. Natl. Acad. Sci. USA 2011, 108 (Suppl. 1), 4653-4658. [CrossRef] [PubMed]

169. Bidart, G.N.; Rodriguez-Diaz, J.; Monedero, V.; Yebra, M.J. A unique gene cluster for the utilization of the mucosal and human milk-associated glycans galacto-N-biose and lacto-N-biose in Lactobacillus casei. Mol. Microbiol. 2014, 93, 521-538. [CrossRef] [PubMed]

170. Jost, T.; Lacroix, C.; Braegger, C.; Chassard, C. Impact of human milk bacteria and oligosaccharides on neonatal gut microbiota establishment and gut health. Nutr. Rev. 2015, 73, 426-437. [CrossRef] [PubMed]

171. Newburg, D.S. Oligosaccharides in human milk and bacterial colonization. J. Pediatr. Gastroenterol. Nutr. 2000, 30 (Suppl. 2), S8-S17. [CrossRef] [PubMed]

172. Collado, M.C.; Laitinen, K.; Salminen, S.; Isolauri, E. Maternal weight and excessive weight gain during pregnancy modify the immunomodulatory potential of breast milk. Pediatr. Res. 2012, 72, 77-85. [CrossRef] [PubMed] 
173. Aakko, J.; Kumar, H.; Rautava, S.; Wise, A.; Autran, C.; Bode, L.; Isolauri, E.; Salminen, S. Human milk oligosaccharide categories define the microbiota composition in human colostrum. Benef. Microbes 2017, 8, 563-567. [CrossRef] [PubMed]

174. Urbaniak, C.; Cummins, J.; Brackstone, M.; Macklaim, J.M.; Gloor, G.B.; Baban, C.K.; Scott, L.; O'Hanlon, D.M.; Burton, J.P.; Francis, K.P.; et al. Microbiota of human breast tissue. Appl. Environ. Microbiol. 2014, 80, 3007-3014. [CrossRef] [PubMed]

175. Koropatkin, N.M.; Cameron, E.A.; Martens, E.C. How glycan metabolism shapes the human gut microbiota. Nat. Rev. Microbiol. 2012, 10, 323-335. [CrossRef] [PubMed]

176. Tailford, L.E.; Crost, E.H.; Kavanaugh, D.; Juge, N. Mucin glycan foraging in the human gut microbiome. Front. Genet. 2015, 6, 81. [CrossRef] [PubMed]

177. Ottman, N. Host Immunostimulation and Substrate Utilization of the Gut Symbiont Akkermansia muciniphila. Ph.D. Thesis, Wageningen University, Wageningen, The Netherlands, 2015.

178. Mateo Anson, N.; van den Berg, R.; Havenaar, R.; Bast, A.; Haenen, G.R.M.M. Bioavailability of ferulic acid is determined by its bioaccessibility. J. Cereal Sci. 2009, 49, 296-300. [CrossRef]

179. Rajilic-Stojanovic, M.; Maathuis, A.; Heilig, H.G.; Venema, K.; de Vos, W.M.; Smidt, H. Evaluating the microbial diversity of an in vitro model of the human large intestine by phylogenetic microarray analysis. Microbiology 2010, 156, 3270-3281. [CrossRef] [PubMed]

180. Molly, K.; Vande Woestyne, M.; Verstraete, W. Development of a 5-step multi-chamber reactor as a simulation of the human intestinal microbial ecosystem. Appl. Microbiol. Biotechnol. 1993, 39, 254-258. [CrossRef] [PubMed]

181. Van den Abbeele, P.; Roos, S.; Eeckhaut, V.; MacKenzie, D.A.; Derde, M.; Verstraete, W.; Marzorati, M.; Possemiers, S.; Vanhoecke, B.; Van Immerseel, F.; et al. Incorporating a mucosal environment in a dynamic gut model results in a more representative colonization by lactobacilli. Microb. Biotechnol. 2012, 5, 106-115. [CrossRef] [PubMed]

182. Van den Abbeele, P.; Grootaert, C.; Marzorati, M.; Possemiers, S.; Verstraete, W.; Gérard, P.; Rabot, S.; Bruneau, A.; El Aidy, S.; Derrien, M.; et al. Microbial Community Development in a Dynamic Gut Model Is Reproducible, Colon Region Specific, and Selective for Bacteroidetes and Clostridium Cluster IX. Appl. Environ. Microbiol. 2010, 76, 5237-5246. [CrossRef] [PubMed]

183. Van Herreweghen, F.; Van den Abbeele, P.; De Mulder, T.; De Weirdt, R.; Geirnaert, A.; Hernandez-Sanabria, E.; Vilchez-Vargas, R.; Jauregui, R.; Pieper, D.H.; Belzer, C.; et al. In vitro colonisation of the distal colon by Akkermansia muciniphila is largely mucin and $\mathrm{pH}$ dependent. Benef. Microbes 2017, 8, 81-96. [CrossRef] [PubMed]

184. Kemperman, R.A.; Gross, G.; Mondot, S.; Possemiers, S.; Marzorati, M.; Van de Wiele, T.; Doré, J.; Vaughan, E.E. Impact of polyphenols from black tea and red wine/grape juice on a gut model microbiome. Food Res. Int. 2013, 53, 659-669. [CrossRef]

185. Garcia-Villalba, R.; Vissenaekens, H.; Pitart, J.; Romo-Vaquero, M.; Espin, J.C.; Grootaert, C.; Selma, M.V.; Raes, K.; Smagghe, G.; Possemiers, S.; et al. Gastrointestinal Simulation Model TWIN-SHIME Shows Differences between Human Urolithin-Metabotypes in Gut Microbiota Composition, Pomegranate Polyphenol Metabolism, and Transport along the Intestinal Tract. J. Agric. Food Chem. 2017, 65, 5480-5493. [CrossRef] [PubMed]

186. Van den Abbeele, P.; Belzer, C.; Goossens, M.; Kleerebezem, M.; De Vos, W.M.; Thas, O.; De Weirdt, R.; Kerckhof, F.M.; Van de Wiele, T. Butyrate-producing Clostridium cluster XIVa species specifically colonize mucins in an in vitro gut model. ISME J. 2013, 7, 949-961. [CrossRef] [PubMed]

(C) 2018 by the authors. Licensee MDPI, Basel, Switzerland. This article is an open access article distributed under the terms and conditions of the Creative Commons Attribution (CC BY) license (http://creativecommons.org/licenses/by/4.0/). 